\title{
Hybrid Neural Fuzzy Design-Based Rotational Speed Control of a Tidal Stream Generator Plant
}

\author{
Khaoula Ghefiri ${ }^{1,2}, * \mathbb{C}$, Izaskun Garrido ${ }^{2} \mathbb{D}$, Soufiene Bouallègue ${ }^{1}$, Joseph Haggège ${ }^{1}$ and \\ Aitor J. Garrido ${ }^{2}$ \\ 1 Laboratory of Research in Automatic Control-LA.R.A, National Engineering School of Tunis (ENIT), \\ University of Tunis El Manar, BP 37, Le Belvédère, 1002 Tunis, Tunisia; \\ soufiene.bouallegue@issig.rnu.tn (S.B.); joseph.haggege@enit.rnu.tn (J.H.) \\ 2 Automatic Control Group-ACG, Department of Automatic Control and Systems Engineering, \\ Engineering School of Bilbao, University of the Basque Country, 48012 Bilbao, Spain; \\ izaskun.garrido@ehu.es (I.G.); aitor.garrido@ehu.es (A.J.G.) \\ * Correspondence: kghefiri001@ikasle.ehu.eus; Tel.: +34-94-601-4443
}

Received: 20 August 2018; Accepted: 12 October 2018; Published: 17 October 2018

\begin{abstract}
Artificial Intelligence techniques have shown outstanding results for solving many tasks in a wide variety of research areas. Its excellent capabilities for the purpose of robust pattern recognition which make them suitable for many complex renewable energy systems. In this context, the Simulation of Tidal Turbine in a Digital Environment seeks to make the tidal turbines competitive by driving up the extracted power associated with an adequate control. An increment in power extraction can only be archived by improved understanding of the behaviors of key components of the turbine power-train (blades, pitch-control, bearings, seals, gearboxes, generators and power-electronics). Whilst many of these components are used in wind turbines, the loading regime for a tidal turbine is quite different. This article presents a novel hybrid Neural Fuzzy design to control turbine power-trains with the objective of accurately deriving and improving the generated power. In addition, the proposed control scheme constitutes a basis for optimizing the turbine control approaches to maximize the output power production. Two study cases based on two realistic tidal sites are presented to test these control strategies. The simulation results prove the effectiveness of the investigated schemes, which present an improved power extraction capability and an effective reference tracking against disturbance.
\end{abstract}

Keywords: fuzzy logic control; artificial neural networks control; tidal stream generator; swell effect disturbance; doubly fed induction generator; maximum power point tracking

\section{Introduction}

Renewable energy technologies are being increasingly exploited worldwide. Countries around the world are resorting to integrating renewable energy resources into their energy policy to reduce fossil fuel usage and carbon emissions [1-4]. Electricity demand is growing rapidly as countries develop, with increased use of electricity to meet a range of needs. According to the projections of the International Energy Agency (IEA), the global energy need has increased by about 40\% since 1990, and a $53 \%$ increase is expected by 2030 [5]. This fast-rising energy demand will require some US $\$ 45$ trillion in new infrastructure investment by 2030 [6]. The renewable energy technologies can improve energy security and decrease dependence on fossil fuels. The International Energy Outlook (IEO2016) confirms that these systems are related to a growing renewable energy converters. Renewable energy consumption increases by an average of 2.6\% per year between 2012 and 2040 [7]. The technical potential for renewable energy is far greater than current human energy use, and studies suggest it could supply $95 \%$ of global energy demand by 2050 , and double its current share by 2030 , at a 
relatively low net cost [8,9]. Marine renewable energy has become the focus of national research and development because of its abundant, renewable, and non-polluting characteristics [10-12]. Tidal energy represents an important energy source as the tidal energy potential is estimated to be around $450 \mathrm{TWh}$ /year, with about $24 \mathrm{TWh}$ /year on the European coasts [13].

Among marine renewable energy converters, Tidal Stream Generator (TSG) promises to be an environmentally friendly way to generate renewable electric energy with no emission of greenhouse gases during normal operation [14,15]. The horizontal axis tidal stream turbine has apparent similarities with the wind turbine. Nevertheless, they have different operational behaviors. In normal conditions, the fluid is over eight hundred times $(1025 / 1.225=837)$ denser than the air [16]. This is due to the huge kinetic energy density of the water. Therefore, at equal power, the tidal turbine will be more compact than a wind turbine. This will lead to a significant difference in the rotor size [17]. Consequently, the advantages of these opposing views will appear in construction, transportation, and charge of installation. In addition, the differences are mainly in the load design, size, and the inertia of the rotor. These characteristics are figured in different operating conditions. In effect, studies demonstrate that variations of the rotational speed for a TST are higher than for a windmill system, despite the perturbation in the wind speed is much higher than that of marine current [16]. Concerning the tidal stream converters, the swell effect is supposed to be the most disturbing phenomenon for the tidal current speed input [18]. This fluctuation will affect the harnessed output power.

In this area of research, control strategies have a valuable role to enhance the dynamic behavior of the TSG plant. In this context, several control approaches have been used. The Maximum Power Point Tracking (MPPT) strategy is employed to search the maximum harvested power from tides and tracking the Optimal Regimes Characteristic (ORC) operation [19]. Other research focused on the control of the active and reactive powers through the Doubly Fed Induction Generator (DFIG) by the use of the Rotor Side Converter (RSC) and the Grid Side Converter (GSC). The RSC control is used to keep the generator speed at its reference signal and the GSC control is dedicated to ensuring that the DC-link voltage remains constant $[20,21]$. In the literature, the PI controller has been used to control the operation of the marine current turbine through the back-to-back power converter aiming to maximize the captured energy [22]. One can envisage two designs: the torque and rotational speed control loops. However, the torque control loop is sensitive to the parametric variations and the turbulent tidal resource [23]. In addition, advanced control approaches can be employed to provide better performance especially to ensure the robustness under the modeling uncertainties [24,25]. In this framework, the sliding mode control approach is a suitable method for nonlinear systems [26]. It has been used in the field of marine energy conversion [27]. Its robustness to the disturbances and parametric uncertainties renders unnecessary a precise knowledge of the system. However, the main drawback of this method is the chattering phenomenon which is the high-frequency oscillations. This can negatively affect the generator because of discontinuous control. Many approaches were proposed to deal with this drawback as presented in [28]. Furthermore, the artificial intelligence techniques are capable of handling nonlinear problems in various signal processing applications, from pattern recognition and extended to renewable energy converters [29]. An artificial neural network is considered a technique which is well accepted for nonlinear statistical adjustment applications [30]. As discussed in [31], the Artificial Neural Networks (ANN) technique is used to more accurately determine the wind speed distribution law of a site, enabling the better assessment of wind energy potential and wind generator performances. The approach enables wind speed prediction with less errors. An application of using neural networks in wave energy systems is detailed in [32], where the assessment of the wave energy potential in near shore coastal areas is investigated by means of ANNs. The ANN model developed forecast wave energy potential with great accuracy. The Fuzzy Gain Scheduling (FGS) technique has been used as well for renewable energy converters. The MPPT controller for photovoltaic systems using an FGS strategy has been studied in [33]. This approach creates an adaptive MPPT controller and achieves better overall system performance. Furthermore, the proposed technique detailed in [34] is applied to design FGS-PID (Proportional Integral Derivative) 
controllers of superconducting magnetic energy storage for power system stabilization. The study confirms that the controller provides high robustness under various operating conditions and large disturbances. From the benefits of both advanced approaches, which are the ANN and FGS, this study focuses on the power output improvement of the TSG system by implementing a hybrid neural fuzzy design.

The main application of the proposed control is affected by the change in velocities that are not predictable by astronomical tide-in particular, the swell effect phenomenon. For that reason, the robustness of the investigated control strategies has been compared by acquiring data from realistic tidal site in order to show how much energy will be saved. In particular, the novel hybrid Neural Fuzzy design is investigated to reach the power output improvement extraction by varying the rotational speed. The Artificial Neural Networks (ANN) based-MPPT approach has the advantage to approximate and interpolate multi-variate data that require huge databases. Furthermore, the fuzzy gain scheduling based control eliminates the fixed gains during operation. Therefore, the proposed fuzzy block will provide the adaptive change of controller gains which adequately vary according the variable tidal speed. In the operation in variable speed, the FGS-PI-based control is applied to the RSC. This enables the TSG to track the MPPT strategy. The MPPT approach uses a multilayer feed-forward ANN that enhances a fuzzy rotational speed controller. The aim of this command is to control the TSG plant, which, at each tidal velocity, must follow the optimal rotational speed where the maximum generated power is satisfied. The analysis of the investigated control approaches has been tested in the case of an irregular tidal resource and the occurrence of a disturbance during normal operation.

The rest of this article is structured as follows. In Section 2, the TSG system is described and modeled. Section 3 is devoted to the control design of the MPPT-based ANN and the FGS-based rotational speed control. In Section 4, the control robustness and disturbance rejection are investigated. Two study cases are presented and discussed using numerical input and real measured input. Finally, concluding discussions are drawn in Section 5.

\section{Model Statement}

The hydrodynamic turbine design is complex due to the changes in the non-constant current tidal and the direction, and the effect of the fluid depth. Therefore, the modeling assumptions are related to tidal turbine hydrodynamics, considering a constant thrust loading at the disk. In addition, the current speed at the disk is the average of the upstream and downstream currents $[15,35]$. The topology of the TSG system is shown in Figure 1. It consists of a DFIG based on a Tidal Stream Turbine (TST). The configuration of the DFIG allows variable speed operation on a specific operation range. The connection to the grid is done through the stator of the DFIG via a transformer, while the DFIG is connected to the grid through the power electronic converters.

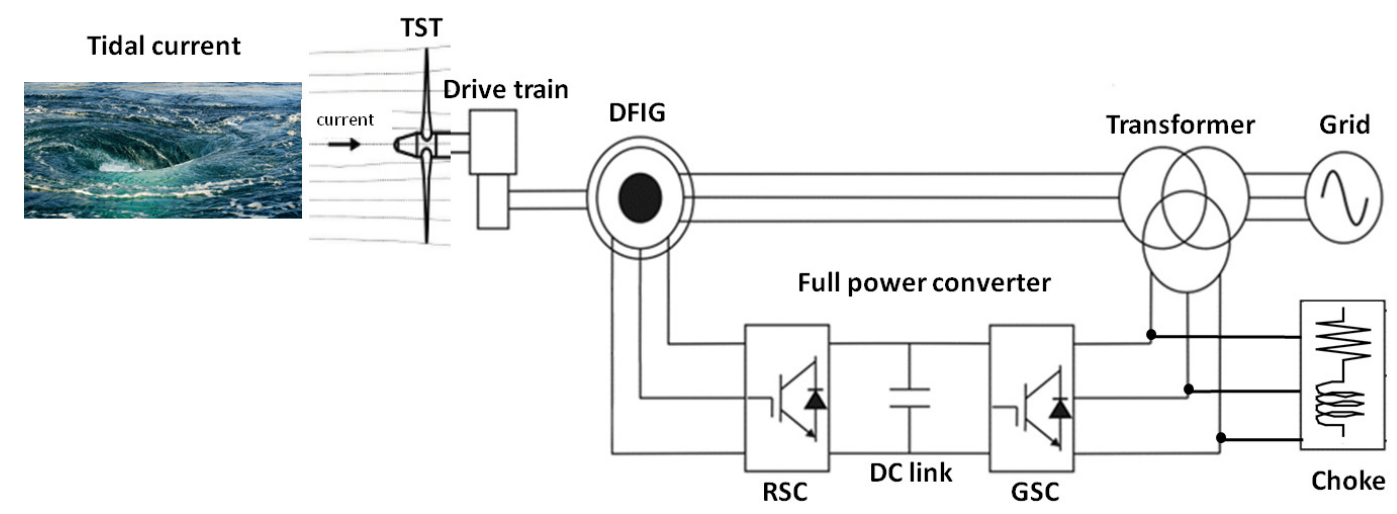

Figure 1. Tidal stream generator global scheme. 


\subsection{Tidal Turbine Model}

The power harnessed from the tidal current speed $V$, can be expressed as follows [36]:

$$
P_{t}=\frac{1}{2} C_{p}(\lambda, \beta) \rho \pi R^{2} V^{3},
$$

where $P_{t}$ denotes the harnessed power from the tidal speed in $(W)$, and $R$ is the radius of the rotor blades expressed in $(m)$.

However, the power captured from the tides cannot be used totally by the turbine because of Betz limit. The power coefficient $C_{p}$ is defined as a function of the blade pitch angle $\beta$ expressed in $(\mathrm{deg})$ and the tip-speed ratio $\lambda$, given as the following equation [37,38]:

$$
\lambda=\frac{\omega_{t} R}{V}
$$

where $\omega_{t}$ is the rotor speed of the tidal turbine defined in $(\mathrm{rad} / \mathrm{s})$.

The generated torque of the tidal turbine, in $(\mathrm{Nm})$, is expressed as follows:

$$
T_{t s t}=\frac{P_{t}}{\omega_{t}}
$$

\subsection{Shaft Model}

The torque produced by the tidal turbine is transmitted to the generator using the drive train, which ensures the connection between the rotor and the generator via a flexible shaft. The model of the drive train shaft used is the two-mass model which is developed using the stiffness coefficient $K_{s h}$ in $(\mathrm{Nm} / \mathrm{rad})$ and the damping coefficient $D_{\mathrm{sh}}$ in $(\mathrm{Nms} / \mathrm{rad})$. The expressions of the developed model are expressed as [39]:

$$
\begin{gathered}
T_{t s t}-T_{t}=2 H_{t} \frac{d \omega_{t}}{d t}, \\
T_{t}=D_{s h}\left(\omega_{t}-\omega_{g}\right)+K_{s h} \int\left(\omega_{t}-\omega_{g}\right) d t, \\
T_{t}-T_{e m}=2 H_{g} \frac{d \omega_{g}}{d t},
\end{gathered}
$$

where $T_{t}$ is the produced torque by the rotor shaft given in $(\mathrm{Nm}), T_{e m}$ is the electromagnetic torque of the generator in $(\mathrm{Nm}), \omega_{g}$ is the generator speed expressed in $(\mathrm{rad} / \mathrm{s})$, and $H_{t}$ and $H_{g}$ are the turbine and the generator inertia constants defined in $s$.

\subsection{DFIG Model}

The functioning in variable speed mode of the tidal turbine based on a DFIG has proven robustness due to the ability to achieve a higher power quality, reduced cost, and improved system efficiency. In addition, the DFIG with a four-quadrant operation enables a decoupled control of the active and reactive powers of the generator [40-42]. The dynamical model of the DFIG is defined using the Park's transformation in $d-q$ as explained in [43]. The equations of the stator voltages and flux, expressed in $(V)$ and in $(W b)$ are given as:

$$
\begin{gathered}
\left\{\begin{array}{l}
U_{s d}=R_{s} I_{s d}+\frac{d \varphi_{s d}}{d t}-\omega_{s} \varphi_{s q}, \\
U_{s q}=R_{s} I_{s q}+\frac{d \varphi_{s q}}{d t}-\omega_{s} \varphi_{s d},
\end{array}\right. \\
\left\{\begin{array}{l}
\varphi_{s d}=L_{s} I_{s d}+L_{m} I_{r d}, \\
\varphi_{s q}=L_{s} I_{s q}+L_{m} I_{r q} .
\end{array}\right.
\end{gathered}
$$


The voltages and flux of the rotor are given as follows:

$$
\begin{gathered}
\left\{\begin{array}{l}
U_{r d}=R_{r} I_{r d}+\frac{d \varphi_{r d}}{d t}-\omega_{r} \varphi_{r q}, \\
U_{r q}=R_{r} I_{r q}+\frac{d \varphi_{r q}}{d t}-\omega_{r} \varphi_{r d},
\end{array}\right. \\
\left\{\begin{array}{l}
\varphi_{r d}=L_{r} I_{r d}+L_{m} I_{s d}, \\
\varphi_{r q}=L_{r} I_{r q}+L_{m} I_{s q} .
\end{array}\right.
\end{gathered}
$$

The generator electromagnetic torque is defined in $d-q$ by Equation (11):

$$
T_{e m}=\frac{3}{2} p L_{m}\left(I_{s q} I_{r d}-I_{s d} I_{r q}\right),
$$

where $I_{s d}, I_{s q}$ are the currents of the stator, $I_{r d}, I_{r q}$ are the currents of the rotor given in $d-q$ in $(A)$, $R_{s}$ and $R_{r}$ are the resistances of the stator and rotor given in $(\Omega), \omega_{s}$ and $\omega_{r}$ are the pulsations of the stator and rotor expressed in $(\mathrm{rad} / \mathrm{s}), L_{s}$ and $L_{r}$ are the inductances of the stator and rotor given in $(H), L_{m}$ is the magnetizing inductance defined in $(H)$ and $p$ is the number of the pole pair.

\subsection{Back-to-Back Converter Model}

The configuration of the DFIG-based TST with the back-to-back power converters allows for decoupling the control for both GSC and RSC components [44,45]. In this subsection, a model of the power converters is presented. The power converters that consist of the RSC and GSC coupled by means of the DC-link as shown in Figure 1. The GSC is controlled thanks to the vector control scheme in order to adjust the voltage of the DC-link-in addition to controlling the flow of the reactive power to ensure the DC voltage adjustments [46]. The control of RSC is proposed to regulate the system in order to achieve the maximum output power production. For that reason, the rotational speed control is investigated using the vector control strategy [43].

The active and reactive powers of the plant, which are defined in $(W)$ and $(V A R)$, are expressed as:

$$
\begin{aligned}
& P_{g}=\frac{3}{2}\left(U_{d g} I_{d g}-U_{q g} I_{q g}\right), \\
& Q_{g}=\frac{3}{2}\left(U_{q g} I_{d g}-U_{d g} I_{q g}\right),
\end{aligned}
$$

where $U_{d g}, U_{q g}$ in $(V)$ and $I_{d g}, I_{q g}$ in $(A)$ are the voltages and currents of the grid expressed in the $d-q$.

The voltages of the d-axis and the grid are aligned, i.e., $U_{d g}=U_{g}$ and $U_{q g}=0$, to reach the voltage oriented control. Thus, the expressions of the active and reactive powers can be given as follows:

$$
\begin{gathered}
P_{g}=\frac{3}{2} U_{g} I_{d g}, \\
Q_{g}=-\frac{3}{2} U_{g} I_{q g} .
\end{gathered}
$$

The expression that links the power saved in the DC-link and the power transmitted to the grid is given as follows:

$$
P_{g}=\frac{3}{2} U_{g} I_{d g}=U_{d c} I_{d c}
$$

where $U_{d c}$ is the voltage of the DC-link given in $(V)$ and $I_{d c}$ is the current flowing in the DC-link in $(A)$.

\section{Control Statement}

Tidal current speed may vary in two ways; on a large time scale by means of the gravitational effort of the sun and the moon. In this case, the current speed profile is composed of spring and neap 
tides and the period occurs each $12 \mathrm{~h}$ and $25 \mathrm{~min}$. On a small time scale, these currents are affected by climate disturbance as the case of swell effect phenomenon which can occur during a period of few seconds. Both time scales should be taken into consideration when implementing the control scheme to drive the TSG in the variable speed mode. The investigated control block for the tidal stream converter system is depicted in Figure 2.

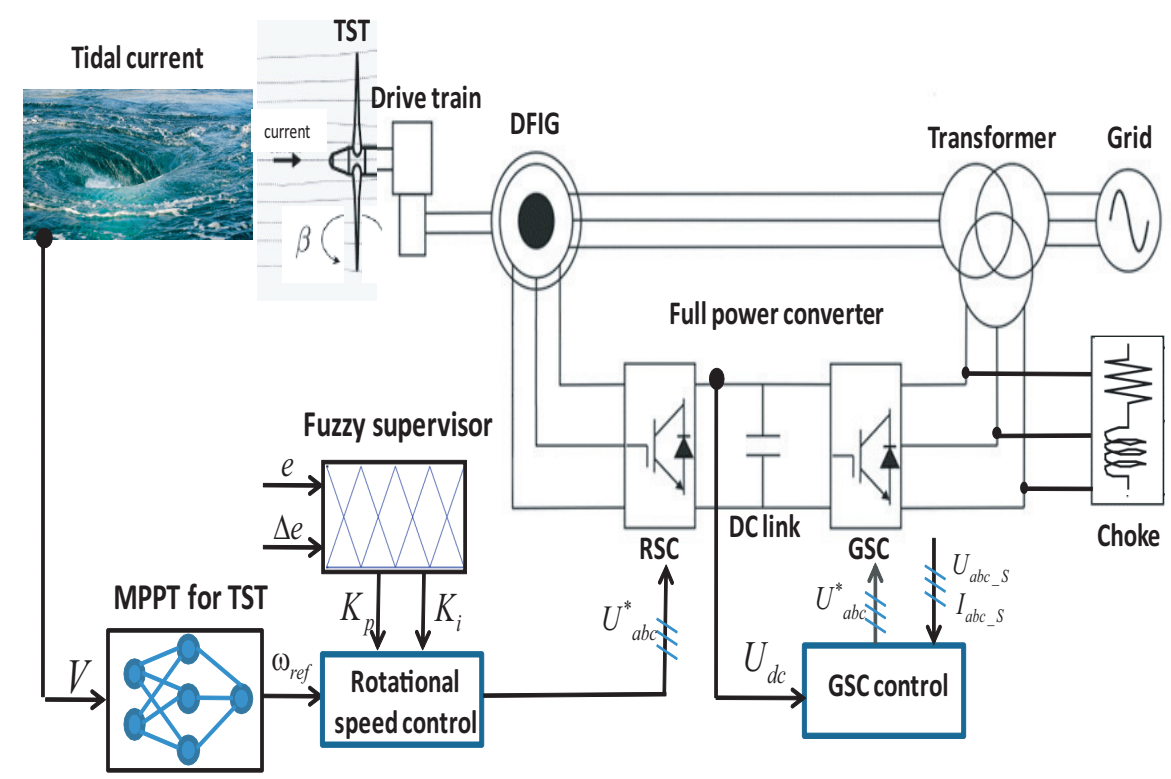

Figure 2. Control strategies scheme description for TSG.

In order to perform the output power's improvement under different input conditions, a novel hybrid rotational speed control is investigated. The MPPT-based ANN approach is designed to provide the suitable rotor speed according to the change of the tidal input. The reference rotational speed is adjusted using a multilayer feed-forward neural network. Then, the proposed fuzzy gain scheduled PI controller is used to regulate the rotational speed. Such a proposed fuzzy supervisor adequately modifies the controller gains providing the control a novel adaptative mechanism to the input parameter changes.

\subsection{ANN-Based Maximum Power Point Tracking Approach}

The MPPT approach has been strongly used to optimize the efficiency of renewable energy plants $[47,48]$. However, this strategy must be adapted to the tidal energy environment according to the control requirements in the TSG system. The MPPT algorithm used in this study is based on an ANN-based approach. The aim of this control strategy is to control the TSG system on the way to follow the optimal rotational speed, which corresponds to the maximum generated power. Figure 3 shows the variation of the generated power as a function of the rotational speed and the tidal current speed.

The system under study consists of a DFIG-based tidal turbine for which the maximum harnessed power is $P_{n}=1.5 \mathrm{MW}$. In order to harness the maximum power from the tides, the power coefficient and thus the tip-speed ratio should be maintained at their maximum values as $C_{p \max }=0.44$ and $\lambda_{\text {opt }}=6.34$, respectively [49]. The structure of the proposed feed-forward neural network is depicted in Figure 4. 


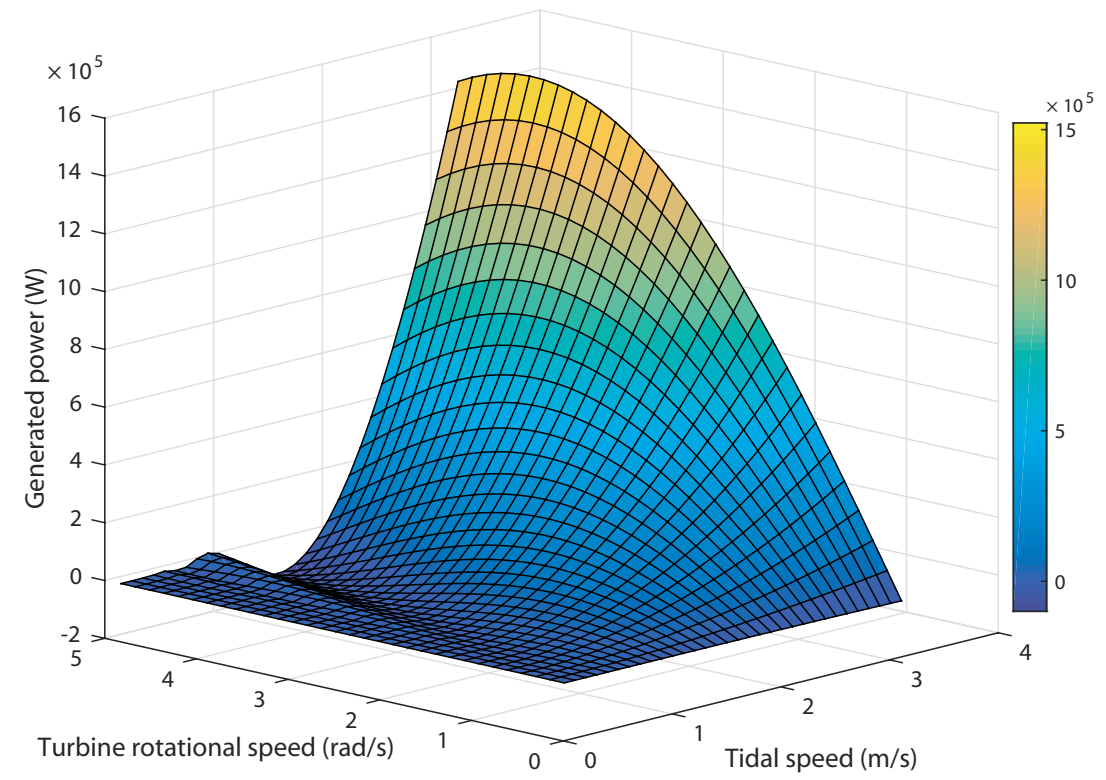

Figure 3. Harnessed output power as a function of the rotor speed for given velocities.

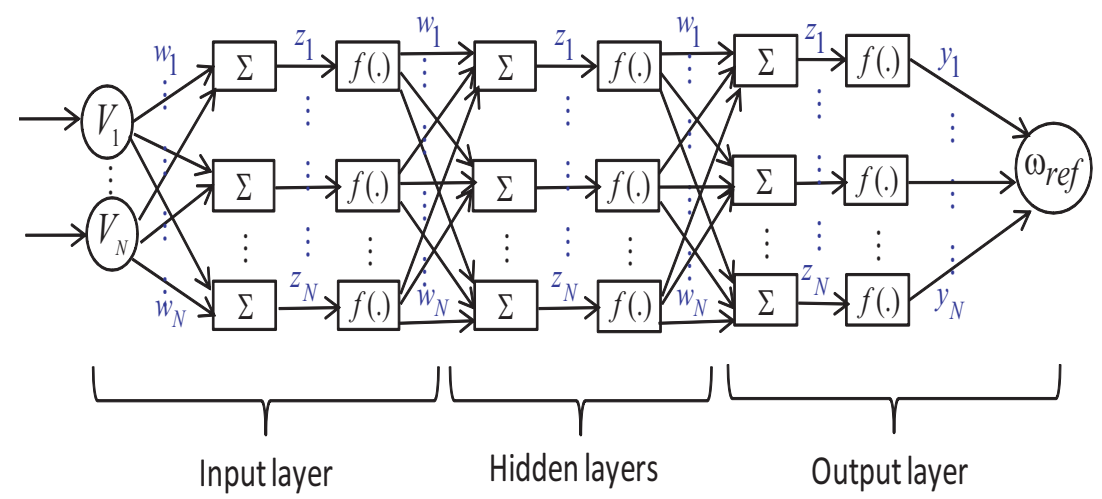

Figure 4. Layout of feed-forward neural network.

The model of a common neuron is given by the following expression:

$$
\begin{aligned}
y_{i} & =\sum_{j=1}^{N} w_{i j} x_{j}+T_{i}^{h}, \\
z_{i} & =f_{i}^{(l)}\left(y_{i}\right),
\end{aligned}
$$

where $z_{i}$ is the output of the $i$ th neuron in the $l$ th hidden layer, $w_{i j}$ are the synaptic weights linking the $j$ th neurons to $i$ th neurons, $f_{i}^{l}($.$) is the activation function of the i$ th neuron of layer $l, i$ is the number of the input neurons, $x_{j}$ are the input neurons, and $T_{i}^{h}$ are the threshold terms of the hidden layer.

The resulting MPPT block adequately adapts the rotational speed reference at each tidal velocity input, so as to maximize the power extracted from the system. Once the network is created and configured, the weights are randomly set at first. The used training method is a Levenberg-Marquardt algorithm $[50,51]$. The used learning algorithm is conceived to adjust the weights to minimize the error for each calculated output and the solution given by the ANN for the adequate input.

The used method is trial-and-error based on a forward strategy process. This begins with an undersized number of neurons in the hidden layer until the training and testing results are ameliorated. This rule uses a statistical analysis to prove the best performance criteria reached. Several tests have been investigated to choose the suitable number of neurons in the hidden layer. The criterion was set according to the smallest Mean Squared Error (MSE) determined. Figure 5 depicts the variation 
of the result of the MPPT block versus the tidal current speed for a various value of neurons in the hidden layer.

a)

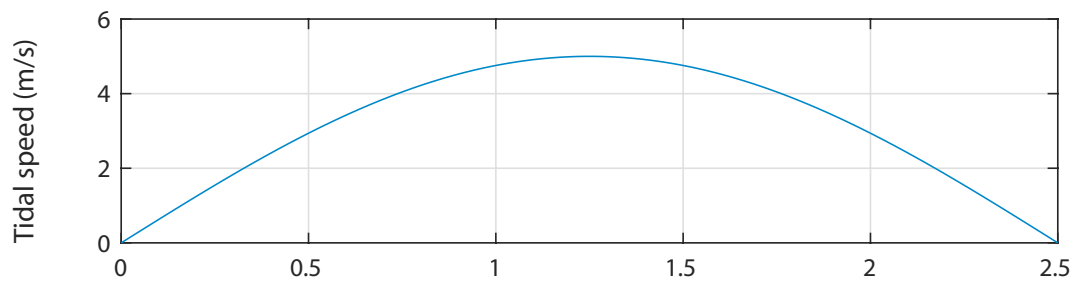

b)

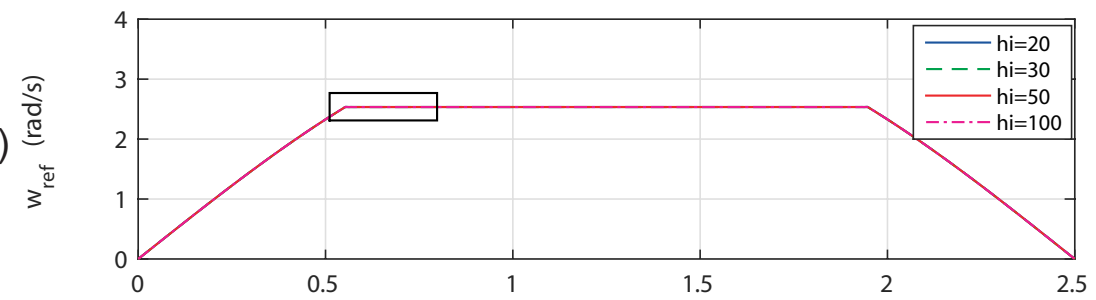

c)

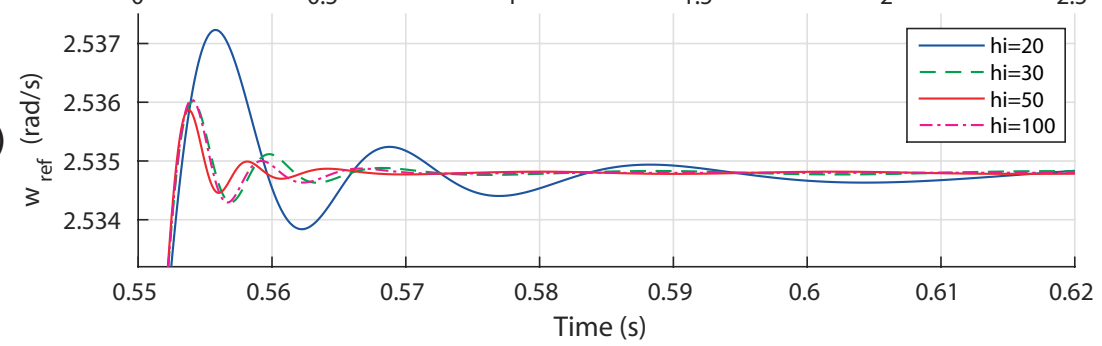

Figure 5. Control performances: (a) tidal speed input; (b) response of the reference rotational speed for different number of neurons; (c) zoom into the reference rotational speed variation for $0.07 \mathrm{~s}$.

The range of variation of $V$ is from 0 to $5 \mathrm{~m} / \mathrm{s}$, which represents a high tidal velocity that can be recorded at the high energetic sites [52]. As it may be seen that, for all tidal velocities less than $3.2 \mathrm{~m} / \mathrm{s}$, the response is regulated to follow the reference. When the tidal velocity is superior to the threshold limit of the rotor speed, it is kept at its maximum value, that is, $2.53 \mathrm{rad} / \mathrm{s}$. The number of neurons in the hidden layer will be chosen to be $h_{i}=50$ as a trade-off between a low number and a transient with small oscillations.

It may be seen in Figure 6 the iteration for which the validation performance is minimal. The best validation performance is $1.407 \times 10^{-7}$ at epoch 1000 . This character displays that the training data admit a good fit.

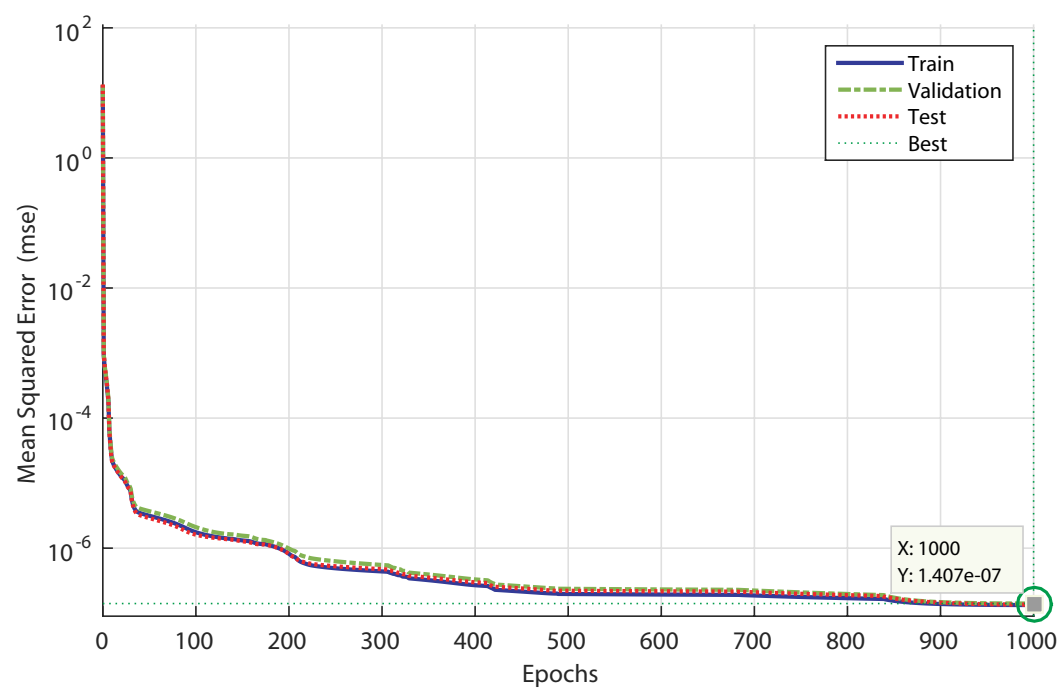

Figure 6. Training performance of the ANN block. 


\subsection{FGS-PI Based-Rotational Speed Control}

The developed block control which is conceived to the RSC is shown in Figure 7. The adequate rotational speed $\omega_{\text {ref }}$ is acquired from the developed ANN based MPPT approach. The control loop of the rotational speed is conceived by means of a fuzzy gain scheduling approach since it is considered as a robust control strategy against uncertainties [53]. Thus, the principle of FGS-PI based control is to refine the parameters of the tuned PI controller to satisfy the required performance $[33,54,55]$.

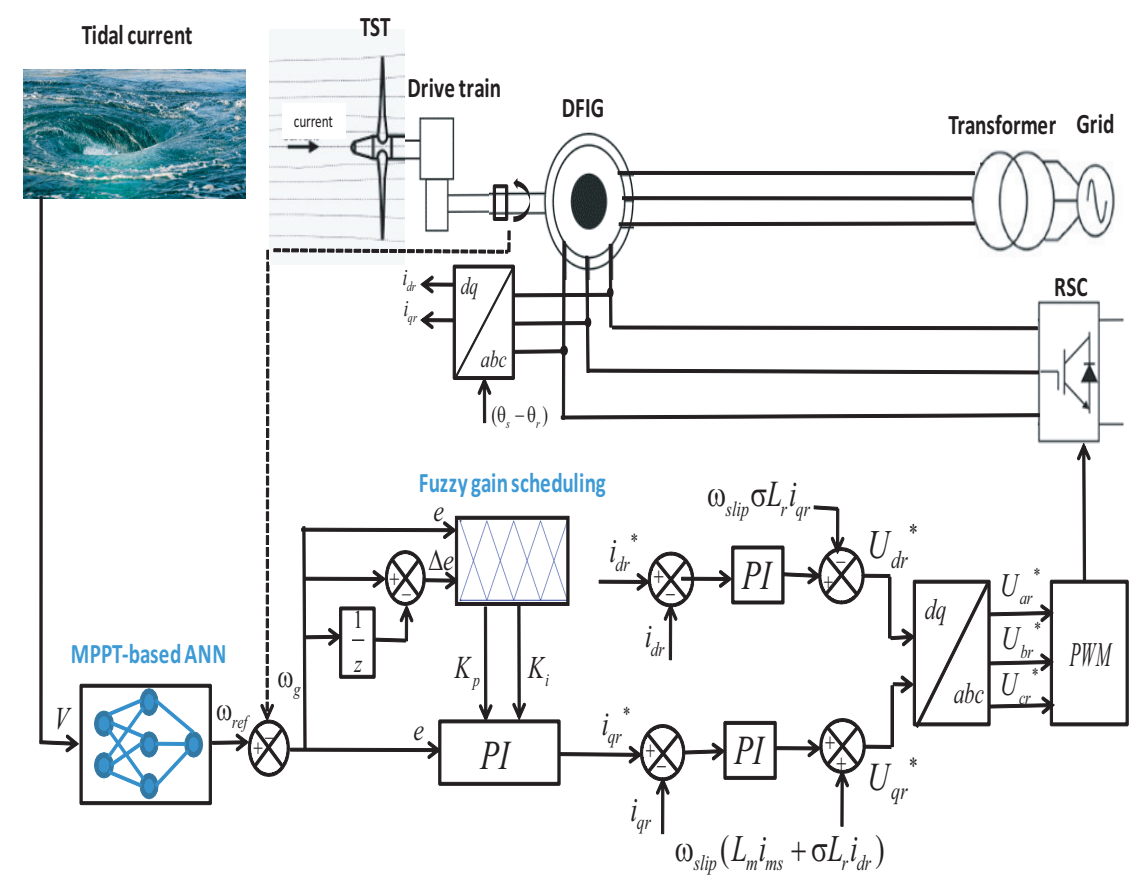

Figure 7. Control scheme of the RSC component.

The discrete-time expression of the PI control law is expressed by the following equation:

$$
u(k)=K_{p} \Delta e(k)+K_{i} T_{s} e(k)+u(k-1),
$$

where $e(k)$ is the error from the adequate rotational speed acquired from the ANN-based MPPT strategy and the actual rotor speed, $\Delta e(k)=e(k)-e(k-1)$ is the variation of the error, $K_{p}$ and $K_{i}$ are the PI controller parameters and $T_{S}$ is the sampling time.

In effect, the fuzzy logic controller acquires the inputs and outputs which should be actual numbers to satisfy the actuators conditions. Thus, the fuzzification and defuzzification process for the input and outputs variables is essential. The aim of the fuzzification is to convert the crisp values to fuzzy linguistic terms in order to apply the fuzzy inferences using the rules. For that reason, the inputs and outputs are normalized in the universe of discourse [56,57].

The fuzzy supervisor includes $e(k)$ and $\Delta e(k)$ the two inputs and two outputs $K_{p}$ and $K_{i}$ as the proportional and integral gains, respectively. These gains are normalized using the linear transformation as follows [53]:

$$
\left\{\begin{array}{l}
K_{p}^{\prime}=\left(K_{p}-K_{p \min }\right) /\left(K_{p \max }-K_{p \min }\right) \\
K_{i}^{\prime}=\left(K_{i}-K_{i \min }\right) /\left(K_{i \max }-K_{i \min }\right)
\end{array}\right.
$$

where $\left[K_{p \min }, K_{p \max }\right]$ and $\left[K_{i \min }, K_{i \max }\right]$ are the tolerable range of the parameters of the controller. 
The gain scheduling of the PI block is obtained adopting the fuzzy rules described by the following equation:

$$
\begin{aligned}
& \text { if } e(k) \text { is } A_{i} \text { and } \Delta e(k) \text { is } B_{i} \text {, } \\
& \text { then } K_{p}^{\prime} \text { is } C_{i} \text { and } K_{i}^{\prime} \text { is } D_{i} \text {, }
\end{aligned}
$$

where $A_{i}, B_{i}, C_{i}$ and $D_{i}$ are the fuzzy sets on the corresponding supporting sets, which $i=1,2, \ldots, m$.

The types of membership functions considered in this study are triangular and trapezoidal, which are uniformly distributed and symmetrical in the universe of discourse. The used linguistic levels are Negative Big (NB), Negative (N), Zero (Z), Positive (P) and Positive Big (PB). The corresponding membership functions related to the inputs $e$ and $\Delta e$ of $A_{i}$ and $B_{i}$ fuzzy sets and to the outputs $K_{p}^{\prime}$ and $K_{i}^{\prime}$ of $C_{i}$ and $D_{i}$ fuzzy sets are illustrated in Figures 8 and 9.

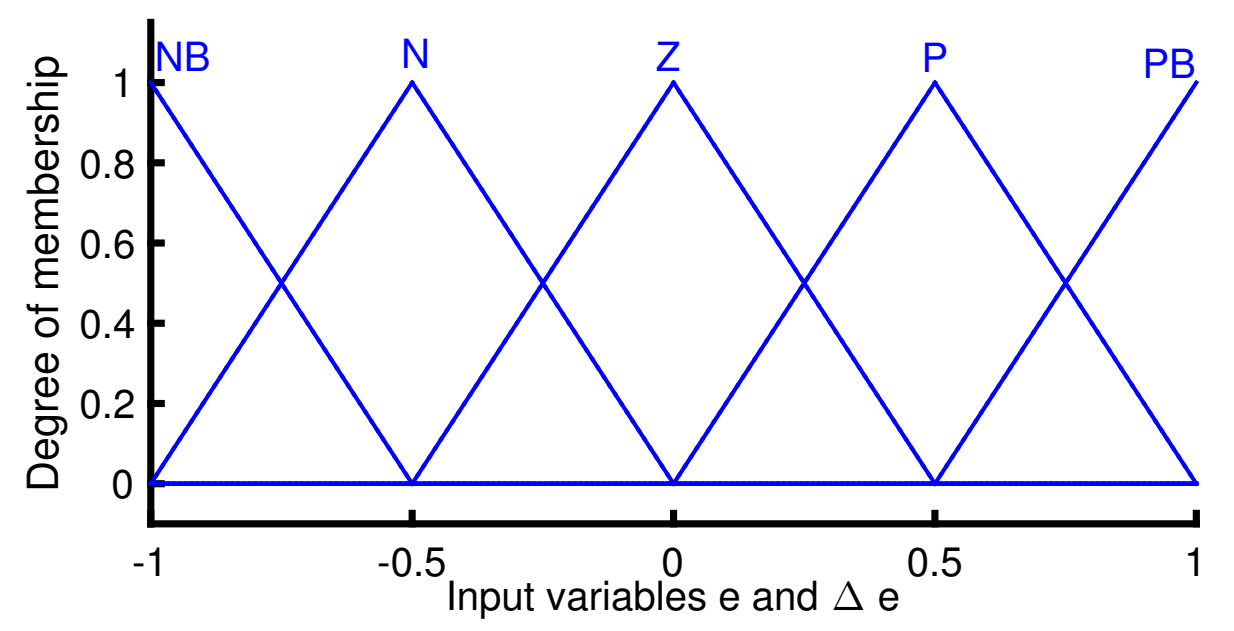

Figure 8. Membership functions for inputs $e$ and $\Delta e$.

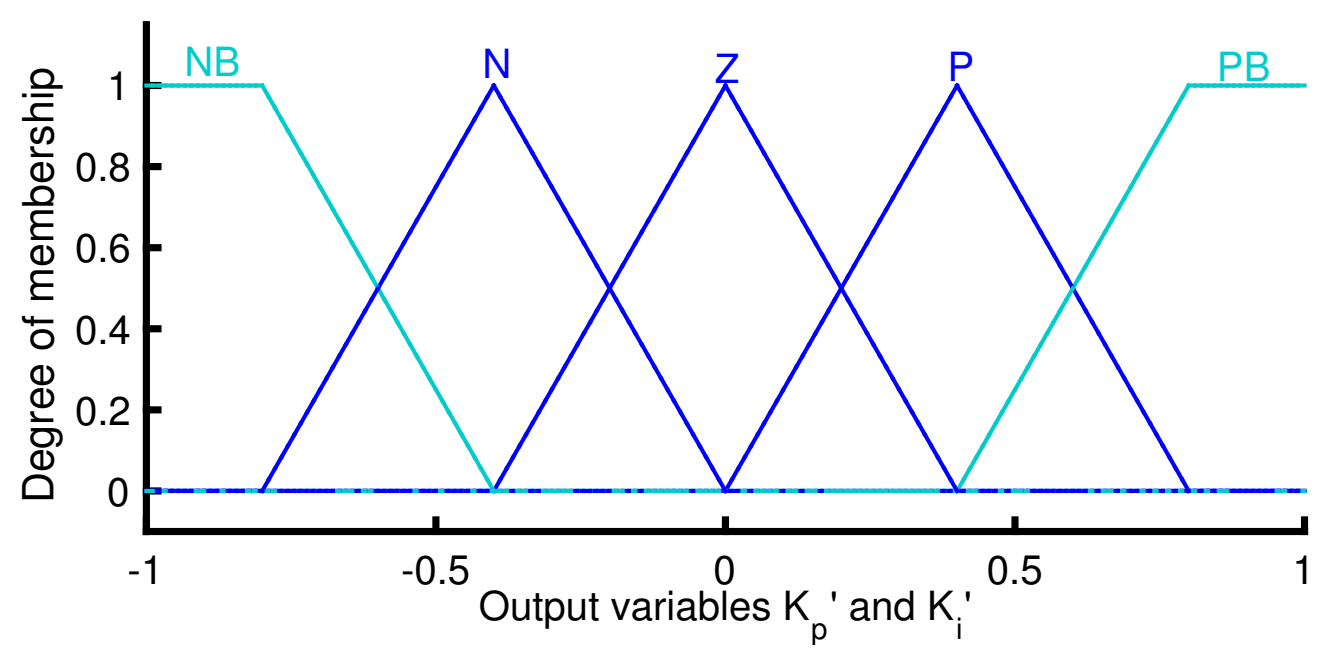

Figure 9. Membership functions for outputs $K_{p}^{\prime}$ and $K_{i}^{\prime}$.

The grade of the membership functions $\mu_{A_{i}}$ and $\mu_{B_{i}}$ are defined as: 


$$
\begin{aligned}
& \mu_{\mathrm{NB}}(X)= \begin{cases}(-2 X-1) & \text { if } X \in(-1,-1 / 2) \\
0 & \text { if } X \geq-1 / 2\end{cases} \\
& \mu_{\mathrm{N}}(X)= \begin{cases}2(X+1) & \text { if } X \in(-1,-1 / 2] \\
-2 X & \text { if } X \in(-1 / 2,0) \\
0 & \text { if } X \geq 0,\end{cases} \\
& \mu_{\mathrm{Z}}(X)= \begin{cases}0 & \text { if } X \leq-1 / 2 \\
(2 X+1) & \text { if } X \in(-1 / 2,0] \\
(1-2 X) & \text { if } X \in(0,1 / 2) \\
0 & \text { if } X \geq 1 / 2\end{cases} \\
& \mu_{P}(X)= \begin{cases}0 & \text { if } X \leq 0 \\
2 X & \text { if } X \in(0,1 / 2 \\
2(1-X) & \text { if } X \in(1 / 2,1),\end{cases} \\
& \mu_{\mathrm{PB}}(X)= \begin{cases}0 & \text { if } X \leq 1 / 2 \\
(2 X-1) & \text { if } X \in(1 / 2,1],\end{cases}
\end{aligned}
$$

where $X$ represents $e$ or $\Delta e$.

In addition, the grade of the membership functions $\mu_{C_{i}}$ and $\mu_{D_{i}}$ are defined as follows:

$$
\begin{aligned}
& \mu_{\mathrm{NB}}(Z)= \begin{cases}1 & \text { if } Z \in[-1,-4 / 5] \\
(-1-5 Z / 2) & \text { if } Z \in[-4 / 5,-2 / 5] \\
0 & \text { if } Z>-2 / 5,\end{cases} \\
& \mu_{\mathrm{N}}(Z)= \begin{cases}0 & \text { if } Z \leq-4 / 5 \\
(5 Z / 2+2) & \text { if } Z \in(-4 / 5,-2 / 5] \\
-5 Z / 2 & \text { if } Z \in(-2 / 5,0) \\
0 & \text { if } Z \geq 0,\end{cases} \\
& \mu_{\mathrm{Z}}(Z)= \begin{cases}0 & \text { if } Z \leq-2 / 5 \\
(5 Z / 2+1) & \text { if } Z \in(-2 / 5,0] \\
(1-5 Z / 2) & \text { if } Z \in(0,2 / 5) \\
0 & \text { if } Z \geq 2 / 5,\end{cases} \\
& \mu_{P}(Z)= \begin{cases}0 & \text { if } Z \leq 0 \\
5 Z / 2 & \text { if } Z \in(0,2 / 5] \\
(2-5 Z / 2) & \text { if } Z \in(2 / 5,4 / 5) \\
0 & \text { if } Z \geq 4 / 5,\end{cases} \\
& \mu_{P \mathrm{~B}}(Z)= \begin{cases}0 & \text { if } Z \leq 2 / 5 \\
(5 Z / 2-1) & \text { if } Z \in(2 / 5,4 / 5] \\
1 & \text { if } Z \in(4 / 5,1],\end{cases}
\end{aligned}
$$

where $Z$ represents $K_{p}^{\prime}$ or $K_{i}^{\prime}$. 
The set of fuzzy rules considered is given in Tables 1 and 2. The proposed rules are gathered in order to adjust the behaviour of the PI controller in accordance with the error $e(k)$ and the error change $\Delta e(k)$.

Table 1. Fuzzy rules for $K_{p}$ parameter.

\begin{tabular}{cccccc}
\hline$e(k) / \Delta e(k)$ & $\mathrm{NB}$ & $\mathrm{N}$ & $\mathrm{Z}$ & $\mathrm{P}$ & $\mathrm{PB}$ \\
\hline $\mathrm{NB}$ & $\mathrm{NB}$ & $\mathrm{NB}$ & $\mathrm{NB}$ & $\mathrm{N}$ & $\mathrm{Z}$ \\
$\mathrm{N}$ & $\mathrm{NB}$ & $\mathrm{N}$ & $\mathrm{N}$ & $\mathrm{N}$ & $\mathrm{Z}$ \\
$\mathrm{Z}$ & $\mathrm{NB}$ & $\mathrm{N}$ & $\mathrm{Z}$ & $\mathrm{P}$ & $\mathrm{PB}$ \\
$\mathrm{P}$ & $\mathrm{Z}$ & $\mathrm{P}$ & $\mathrm{P}$ & $\mathrm{P}$ & $\mathrm{PB}$ \\
$\mathrm{PB}$ & $\mathrm{Z}$ & $\mathrm{P}$ & $\mathrm{PB}$ & $\mathrm{PB}$ & $\mathrm{PB}$ \\
\hline
\end{tabular}

Table 2. Fuzzy rules for $K_{i}$ parameter.

\begin{tabular}{cccccc}
\hline $\boldsymbol{e}(\boldsymbol{k}) / \boldsymbol{\Delta} \boldsymbol{e}(\boldsymbol{k})$ & $\mathrm{NB}$ & $\mathrm{N}$ & $\mathrm{Z}$ & $\mathrm{P}$ & $\mathrm{PB}$ \\
\hline $\mathrm{NB}$ & $\mathrm{PB}$ & $\mathrm{PB}$ & $\mathrm{PB}$ & $\mathrm{N}$ & $\mathrm{NB}$ \\
$\mathrm{N}$ & $\mathrm{PB}$ & $\mathrm{P}$ & $\mathrm{P}$ & $\mathrm{Z}$ & $\mathrm{NB}$ \\
$\mathrm{Z}$ & $\mathrm{P}$ & $\mathrm{P}$ & $\mathrm{Z}$ & $\mathrm{N}$ & $\mathrm{NB}$ \\
$\mathrm{P}$ & $\mathrm{Z}$ & $\mathrm{P}$ & $\mathrm{N}$ & $\mathrm{N}$ & $\mathrm{NB}$ \\
$\mathrm{PB}$ & $\mathrm{Z}$ & $\mathrm{N}$ & $\mathrm{NB}$ & $\mathrm{NB}$ & $\mathrm{NB}$ \\
\hline
\end{tabular}

The truth value of the $i$ th rule is obtained by the product of the truth value of the components of the antecedent clauses as:

$$
\mu_{i}=\mu_{\mathrm{A}_{i}}(e(k)) \cdot \mu_{B_{i}}(\Delta e(k)) .
$$

By using the membership functions, we obtain:

$$
\sum_{i=1}^{m} \mu_{i}=1
$$

thus the defuzzification scheme is defined as:

$$
\left\{\begin{array}{l}
K_{p}^{\prime}=\sum_{i=1}^{m} \mu_{i} \mu_{C_{i}}, \\
K_{i}^{\prime}=\sum_{i=1}^{m} \mu_{i} \mu_{D_{i}} .
\end{array}\right.
$$

The decision-making output is acquired using a Max-Min fuzzy inference where the crisp outputs are obtained using the method of defuzzification and the center of gravity given as follows:

$$
\left\{\begin{array}{l}
K_{p}=K_{p \min }+\left(K_{p \max }-K_{p \min }\right) K_{p}^{\prime} \\
K_{i}=K_{i \min }+\left(K_{i \max }-K_{i \min }\right) K_{i}^{\prime} .
\end{array}\right.
$$

By implementing the fuzzy block using the set of fuzzy rules, the fuzzy surfaces for the outputs $K_{p}$ and $K_{i}$ parameters are illustrated in Figures 10 and 11. 


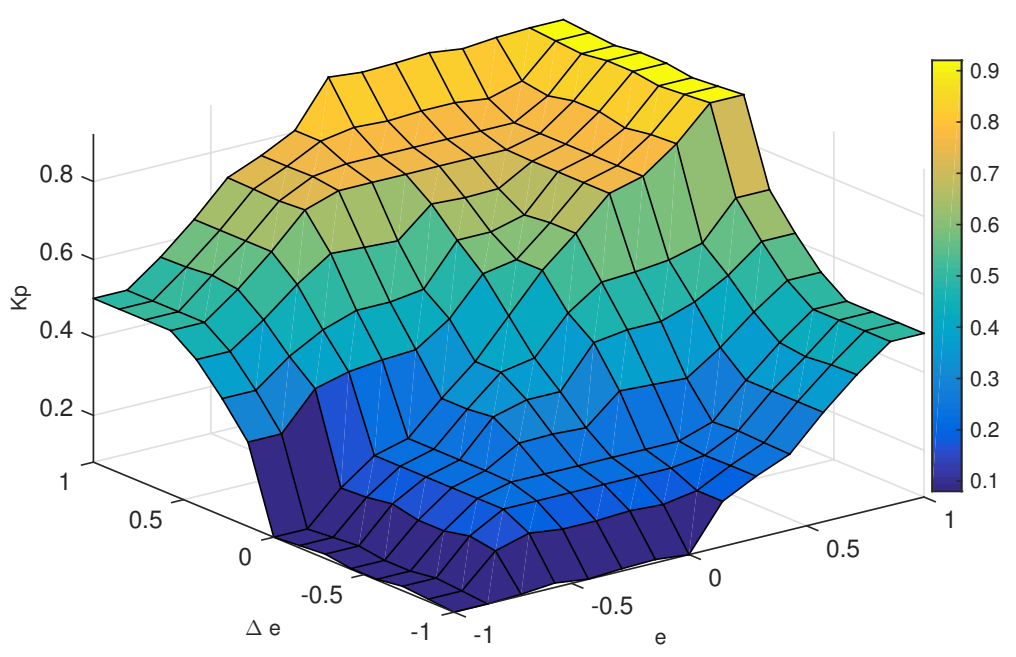

Figure 10. Fuzzy surface for $K_{p}$ gain.

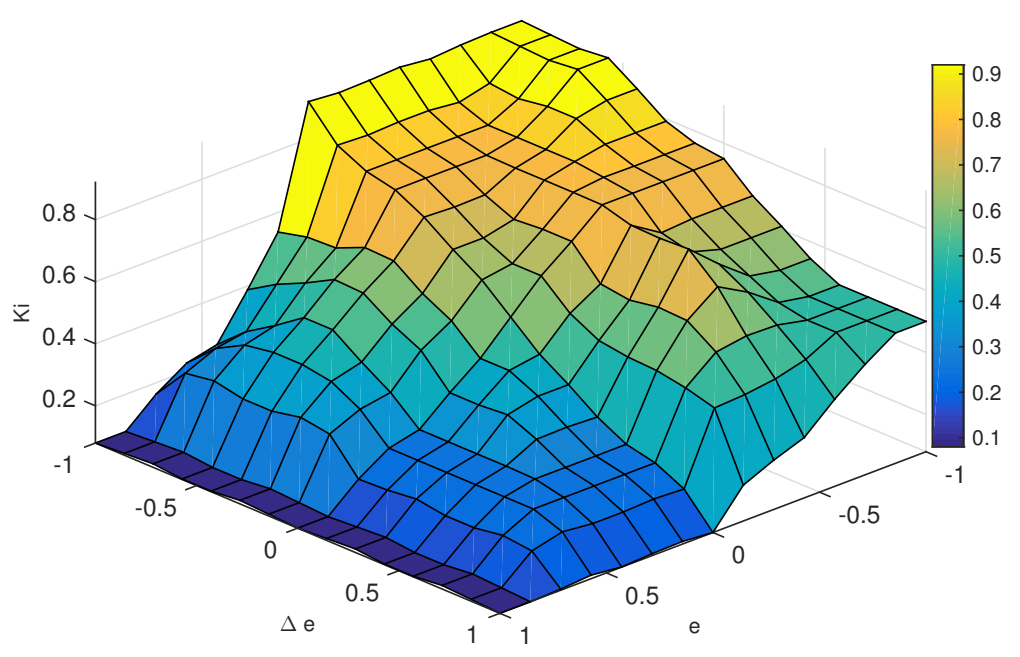

Figure 11. Fuzzy surface for $K_{i}$ gain.

The inner current loops find the rotor voltage reference in $d-q$ frame. The equations that rely on the rotor voltages and currents defined in $(V)$ and in $(A)$ are expressed by Equation (27) as detailed in [43]:

$$
\left\{\begin{array}{l}
U_{d r}=R_{r} i_{d r}+\sigma L_{r} \frac{d i_{d r}}{d t}, \\
U_{q r}=R_{r} i_{q r}+\sigma L_{r} \frac{d i_{r} r}{d t}
\end{array}\right.
$$

where $\sigma$ is the leakage factor.

In addition, the terms of decoupling are joined to the expressions of $U_{d r}^{*}$ and $U_{q r}^{*}$ in order to enhance the transient response of the plant [58]. Thus, the reference voltages of the rotor are expressed by:

$$
\left\{\begin{array}{l}
U_{d r}^{*}=-\omega_{\text {slip }} \sigma L_{r} i_{q r}+\left(K_{P i} e_{d}+K_{I i} \int e_{d} d t\right), \\
U_{q r}^{*}=\omega_{\text {slip }}\left(L_{m} i_{m}+\sigma L_{r} i_{d r}\right)+\left(K_{P i} e_{d}+K_{I i} \int e_{d} d t\right),
\end{array}\right.
$$

where $\omega_{\text {slip }}$ is the angular frequency of slip given in $(\mathrm{rad} / \mathrm{s})$ and $i_{m}$ is the stator magnetizing current supposed as constant. $K_{P i}$ and $K_{I i}$ are the parameters of the controllers.

The method of tuning of the PI controllers is the well-known Ziegler-Nichols method [59]. After that, another refinement of the tuned controller parameters is conceived by means of the robust 
response time algorithm [60]. The voltage references of the rotor are converted to the $a b c$ frame which will be affected to the RSC through the Pulse Width Modulation (PWM) block.

\subsection{GSC Control}

The control of the GSC is developed using the voltage oriented control strategy as shown in Figure 12. This approach admits two PI current controllers and one outer PI voltage controller [36]. The developed block diagram regulates the DC-link voltage $U_{d c}$ and the reactive power $Q_{g}$. The use of the Phase Locked Loop (PLL) block is to save the input signal phase which denotes $\theta_{g}$. The currents and voltages expressed in $d q$ frame are achieved using the Park's transformation.

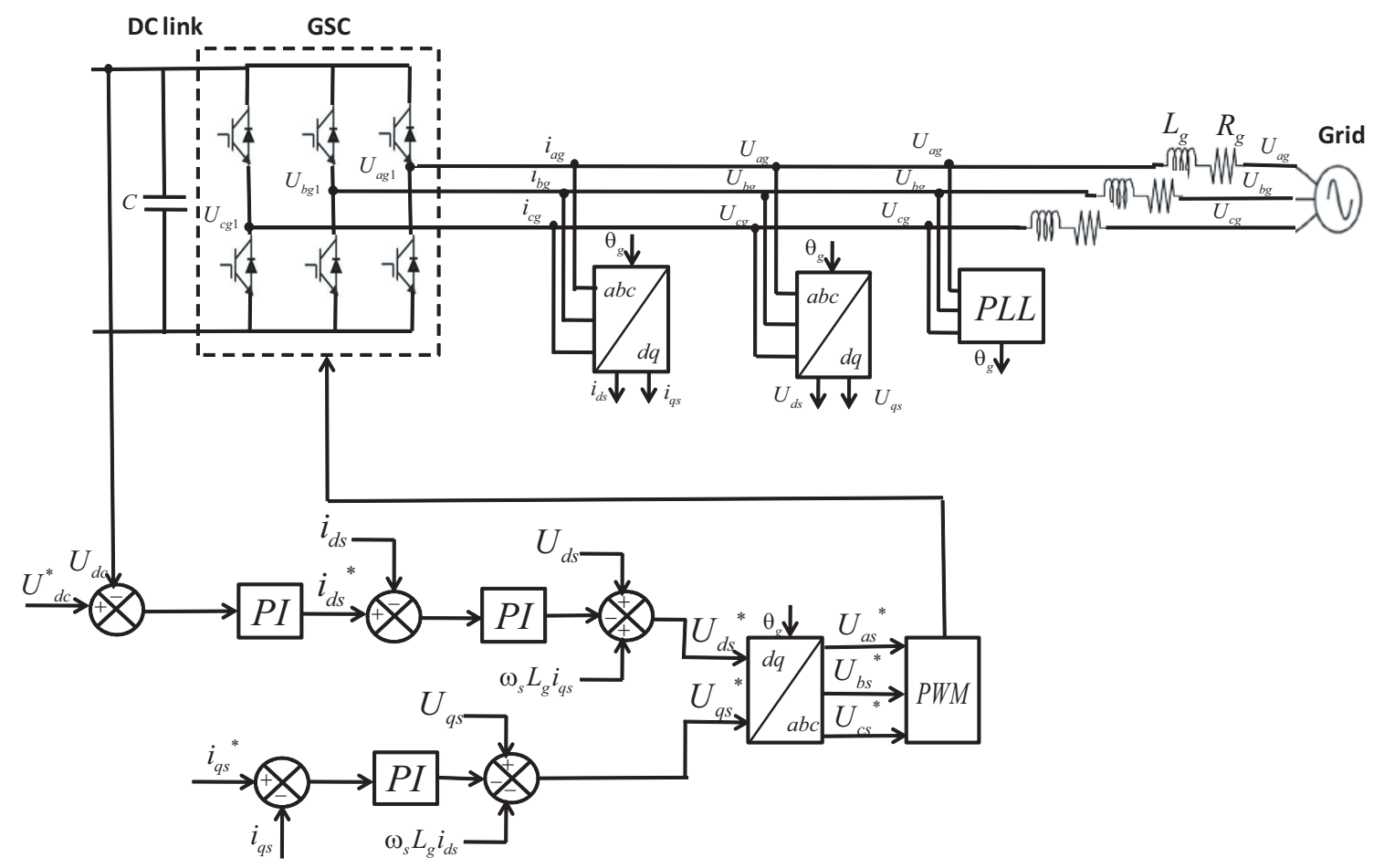

Figure 12. Block control scheme for the GSC component.

The voltages of the grid are expressed using a $d q$ frame as:

$$
\left\{\begin{array}{l}
U_{g d}=i_{d s} R_{g}+L_{g} \frac{d i_{d s}}{d t}-\omega_{s} L_{g} i_{q s}+U_{g d 1}, \\
U_{g q}=i_{q s} R_{g}+L_{g} \frac{d i_{q s}}{d t}-\omega_{s} L_{g} i_{d s}+U_{g q 1},
\end{array}\right.
$$

where $R_{g}$ and $L_{g}$ are the coupling resistance and inductance of the grid, and $U_{g d 1}$ and $U_{g q 1}$ are the terminal voltages of the converter in the $d q$ frame.

The active and reactive powers are regulated through the $d q$ axis currents. The current loops are similar and provide the voltage references of the grid $U_{d s}^{*}$ and $U_{q s}^{*}$ as defined by Equation (30). Thus, as to improve the transient response of the plant, the terms of compensator and feedforward voltages are joined to the command signals:

$$
\left\{\begin{array}{l}
U_{g d}^{*}=U_{g d}+\Omega_{g} L_{g} i_{q}-\left(K_{P i} e_{d}+K_{I i} \int e_{d} d t\right), \\
U_{g q}^{*}=U_{g q}-\Omega_{g} L_{g} i_{d}-\left(K_{P i} e_{q}+K_{I i} \int e_{q} d t\right) .
\end{array}\right.
$$

The voltage control loop is intended to regulate the voltage of the DC-link so as to keep it constant around its reference. The current control loops adjust the currents $i_{d s}$ and $i_{q s}$ in $d q$ frame. The current $i_{q s}$ aims to control the reactive power and the current reference in the q-axis is assumed zero. Likewise, the RSC control and the PI controller gains are determined using the empirical Ziegler-Nichols method [61]. 
After that, the voltage references are converted to the $a b c$ stationary frame, which will acquire the PWM signals for the GSC.

\section{Validation Tests and Discussion}

In this part, based on realistic tidal sites, two study cases are given to test the robustness of the developed control schemes. The demonstrative studies are set to enhance the harnessed power under irregular tidal current speed input. In addition, the fuzzy gain scheduling supervisor was analyzed to favor disturbance rejection. The simulation results have been executed using the TSG system parameters given in Table 3.

Table 3. TSG system parameters.

\begin{tabular}{cccc}
\hline Turbine & Drive-train & DFIG & Converter \\
\hline$\rho=1027 \mathrm{~kg} / \mathrm{m}^{3}$ & $H_{t}=3 \mathrm{~s}$ & $P_{n}=1.5 \mathrm{MW}$ & $V_{d c}=1150 \mathrm{~V}$ \\
$R=8 \mathrm{~m}$ & $H_{g}=0.5 \mathrm{~s}$ & $U_{r m s}=690 \mathrm{~V}$ & $C=0.01 \mathrm{~F}$ \\
$C_{p \max }=0.44$ & $K_{s h}=2 \times 10^{6} \mathrm{Nm} / \mathrm{rad}$ & $f_{r e q}=50 \mathrm{~Hz}$ & \\
$\lambda_{\text {opt }}=6.96$ & $D_{s h}=3.5 \times 10^{5} \mathrm{Nms} / \mathrm{rad}$ & $R_{s}=2.63 \mathrm{~m} \Omega$ & \\
$V_{n}=3.2 \mathrm{~m} / \mathrm{s}$ & & $R_{r}=2.63 \mathrm{~m} \Omega$ & Choke \\
& & $L_{s}=0.168 \mathrm{mH}$ & $R_{g}=0.595 \mathrm{~m} \Omega$ \\
& $L_{r}=0.133 \mathrm{mH}$ & $L_{g}=0.157 \mathrm{mH}$ \\
& $L_{m}=5.474 \mathrm{mH}$ & \\
& $p=2$ & \\
\hline
\end{tabular}

\subsection{Control Robustness against Irregular Tidal Speed with Numerical Input}

So as to examine the robustness of the developed control approaches, a first study case based on the characteristics of a sea state in the winter of the western coast of Europe is investigated. The data of the velocities are based on a mathematical model of the swell disturbance [62]. The swell model is calculated using the first-order Stokes model $[52,63]$. The average height of the highest one-third waves is $3 \mathrm{~m}$ and the average period of these one-third waves is $13.2 \mathrm{~s}$. The sea depth is $30 \mathrm{~m}$. The average tidal current $V_{a v r}=2 \mathrm{~m} / \mathrm{s}$ is chosen in a small time scale. Figure 13 illustrates the tidal velocity profile with a lower speed of $0.6 \mathrm{~m} / \mathrm{s}$ and an upper speed of $3.1 \mathrm{~m} / \mathrm{s}$.

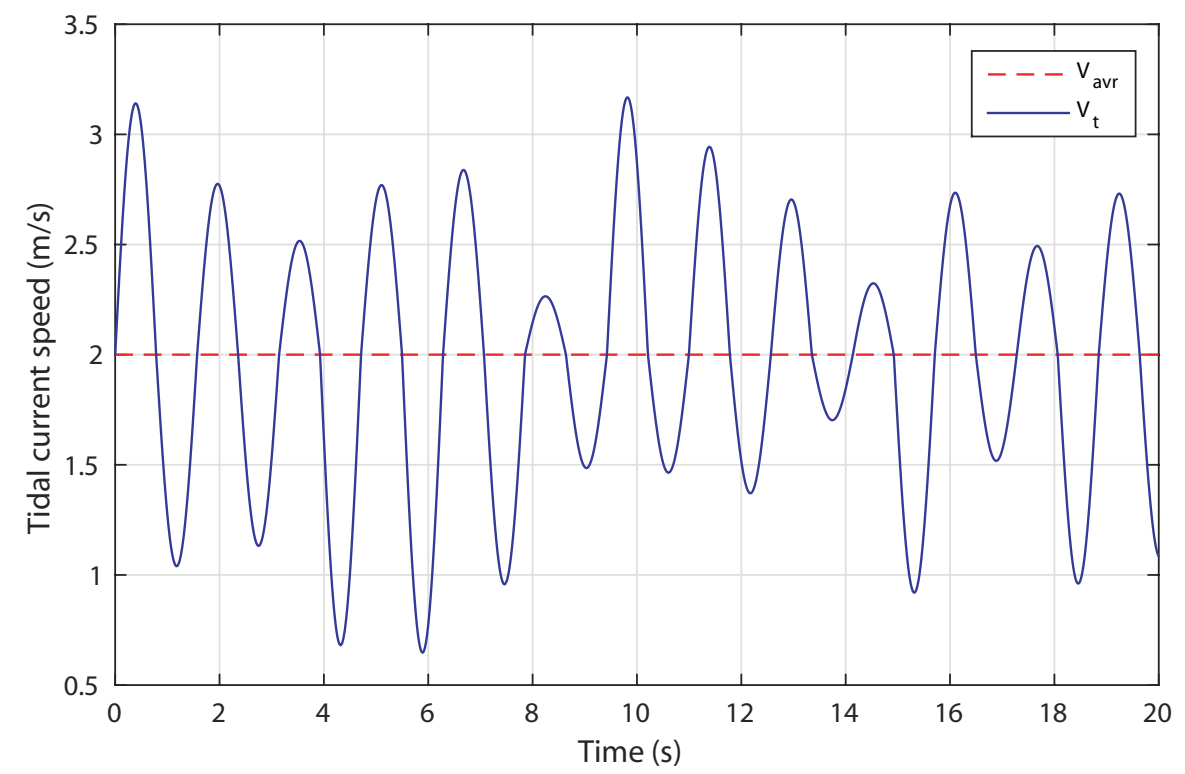

Figure 13. Study case 1: Tidal current speed input.

Figure 14 shows the power coefficient response. In this experiment, it is obvious that the system has good behavior, thus the power coefficient is maintained around its optimum value $C_{p}=0.4373$. 
The $5 \%$ settling time is reached at $0.01 \mathrm{~s}$; it is obvious that the controlled system is able to track fast the desired value in the steady-state regime.

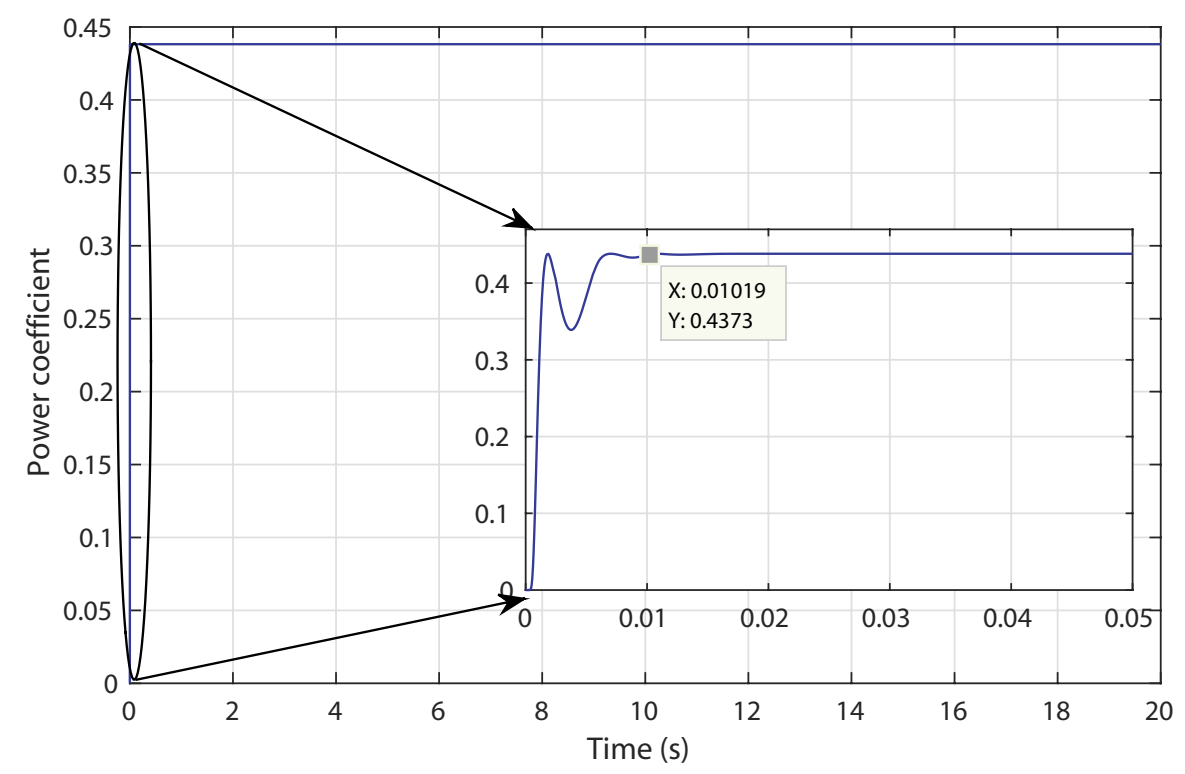

Figure 14. Study case 1: Power coefficient response.

Figure 15 depicts the response of the rotor speed and the adequate signal acquired from the implemented ANN-based MPPT approach. The controller displays a good tracking performance of the adequate rotor speed. This indicates that the FGS-PI controller has a decreased steady-state error because the integral action is adequately changing in accordance to the changes of the input.

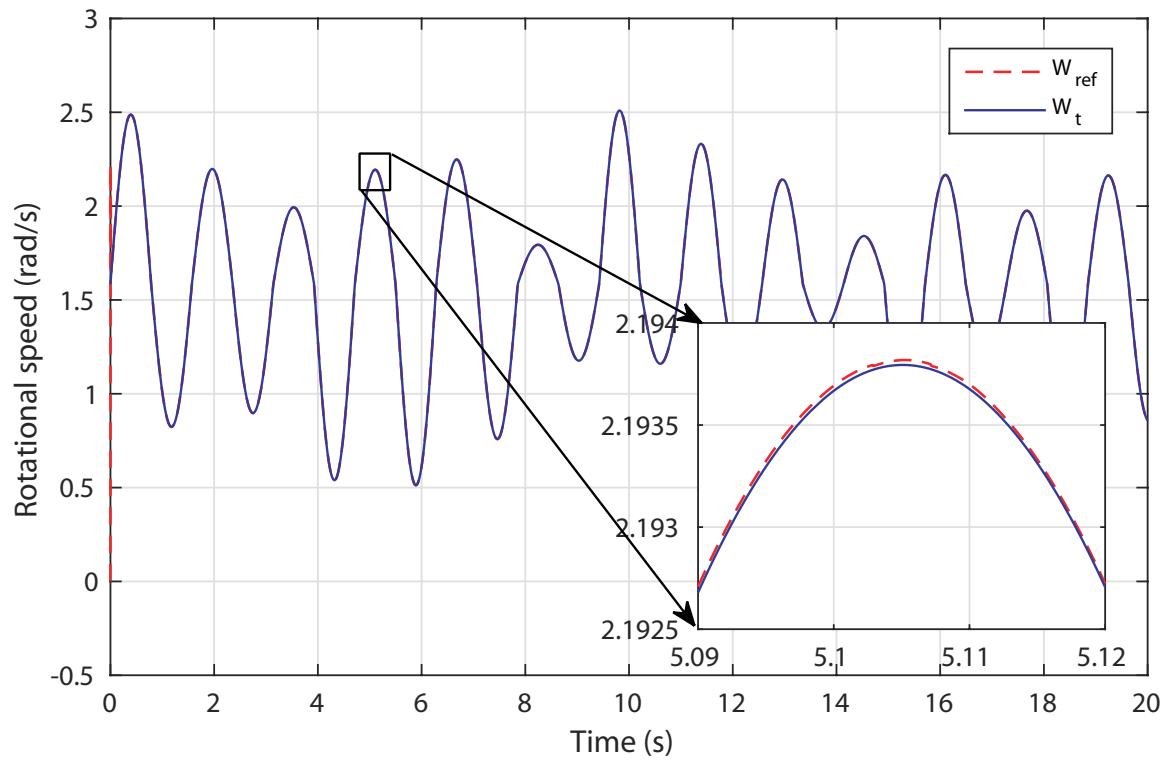

Figure 15. Study case 1: Rotor speed curve and its reference.

The output torque and power variations are shown in Figures 16 and 17. An uncontrolled study case is set to compare the output power. The resulting torque and power change according to the variation of the tidal velocity. The average values of the extracted power are $425 \mathrm{~kW}$ and $549 \mathrm{~kW}$ corresponding to the uncontrolled case and the hybrid neural fuzzy control, respectively. It can be seen that using the developed FGS control provides a good speed tracking performance, which leads to a power generation improvement with a $29.18 \%$. Therefore, the TSG system is capable of augmenting the recuperated output power in case of the swell effect. 


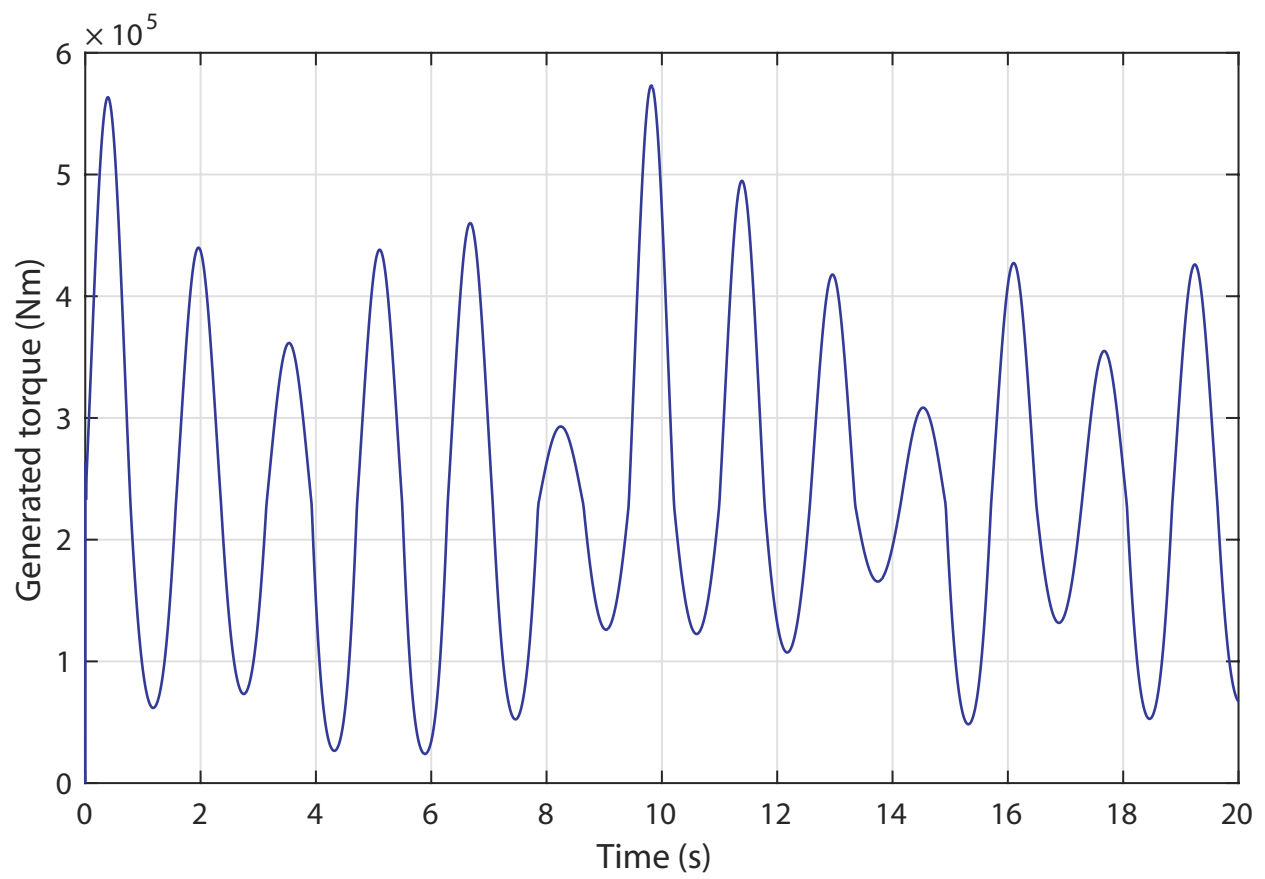

Figure 16. Study case 1: Response of the hydrodynamic torque.

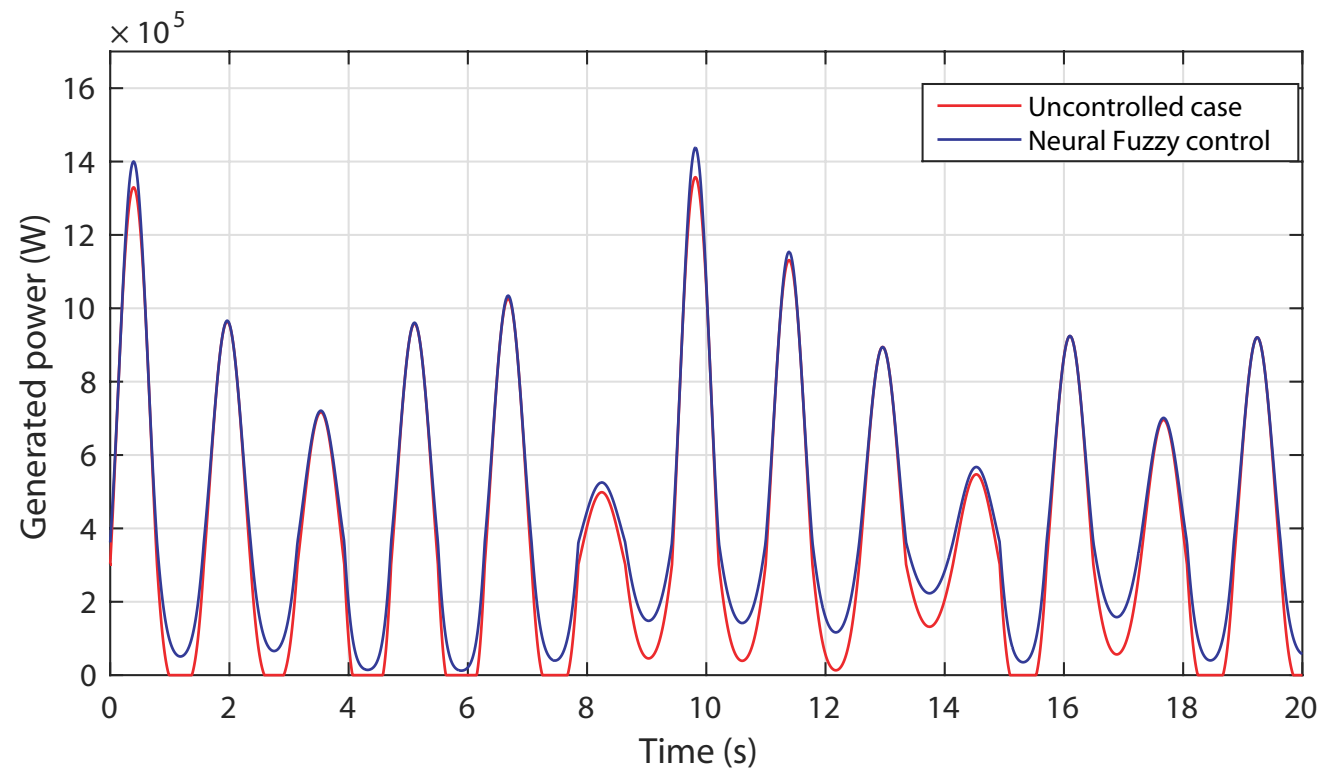

Figure 17. Study case 1: Generated turbine's power curve.

\subsection{Control Robustness against Irregular Tidal Speed with Real Measured Input}

A second realistic tidal site is considered to test the developed control strategies. The station under study is named Middle Ground Shoal which is located in Cook Inlet, USA. According to the National Oceanic and Atmospheric Administration (NOAA), this tidal site can reach important tidal velocities up to $2.3 \mathrm{~m} / \mathrm{s}$ as mentioned in the Cook Inlet 2012 Current Survey as described in [64]. The used data from this tidal site is recorded from 25 June 2012 at 00:00:00 to 26 June 2012 at 23:59:00.

These data are extracted using an Acoustic Doppler Current Profiler [65] with an approximated water depth of $31.15 \mathrm{~m}$ within an interval of $6 \mathrm{~min}$. Figure 18 illustrates the real instantaneous measured tidal currents over two days. Each semidiurnal tide related to spring and neap tides is corresponding to an approximately period of $7 \mathrm{~h}$. It is obviously clear that the oscillation in the current speed profile is important with respect to the average tidal speed which is $1.038 \mathrm{~m} / \mathrm{s}$. 


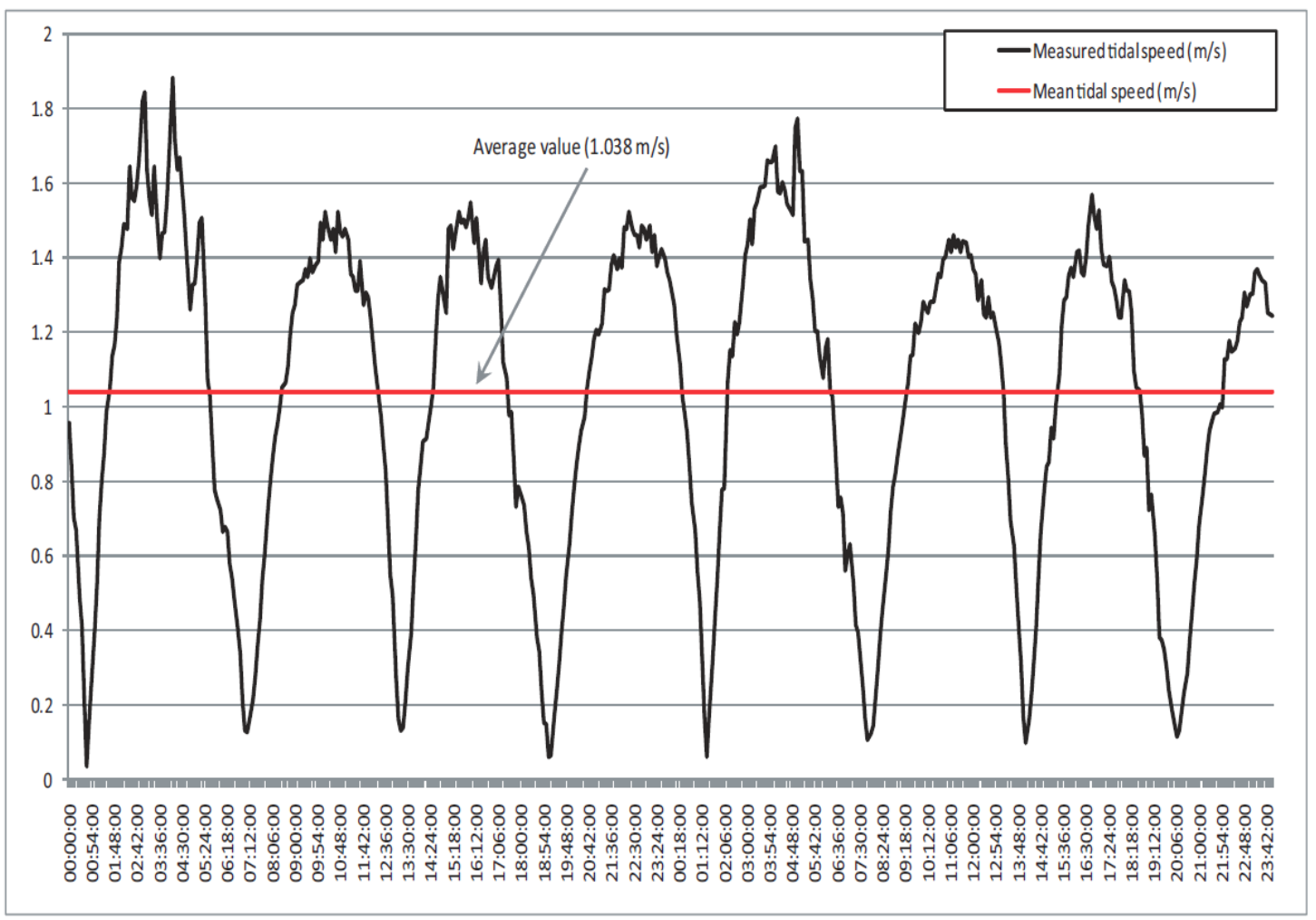

Figure 18. Study case 2: Measured tidal current speed in Cook Inlet from 25 June 2012 at 00:00:00 to 26 June 2012 at 23:59:00.

In the comparative study between the uncontrolled case and the proposed control approaches, the realistic tidal current velocity over the period $00 \mathrm{~h}: 00 \mathrm{~min}$ to $07 \mathrm{~h}: 00 \mathrm{~min}$ of 25 June 2012 is chosen as the input to the implemented model. The response of the power coefficient is depicted in Figure 19. The power coefficient is maintained constant and in the steady state regime reaches a value of 0.4382 at $0.01 \mathrm{~s}$.

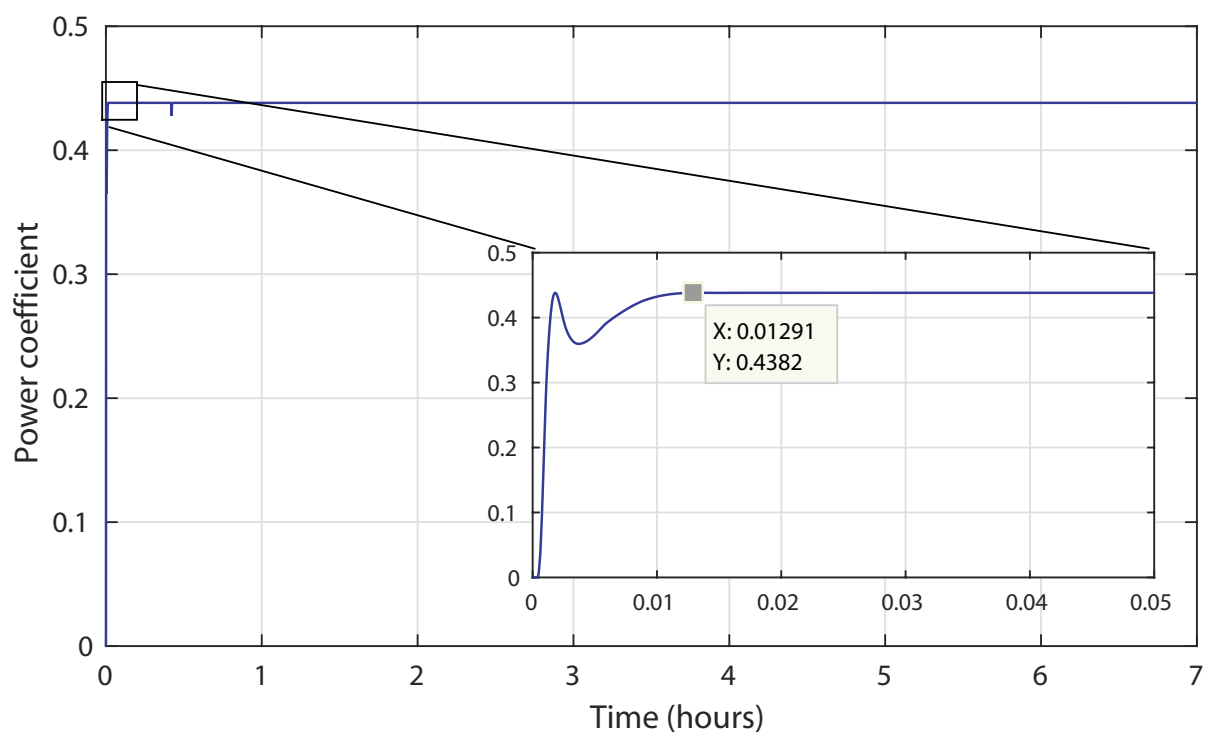

Figure 19. Study case 2: Power coefficient response.

Figure 20 shows the rotational speed curve changing according to the tidal current speed. This result proves that the controller successfully manages to follow the optimal reference provided by the MPPT strategy. 


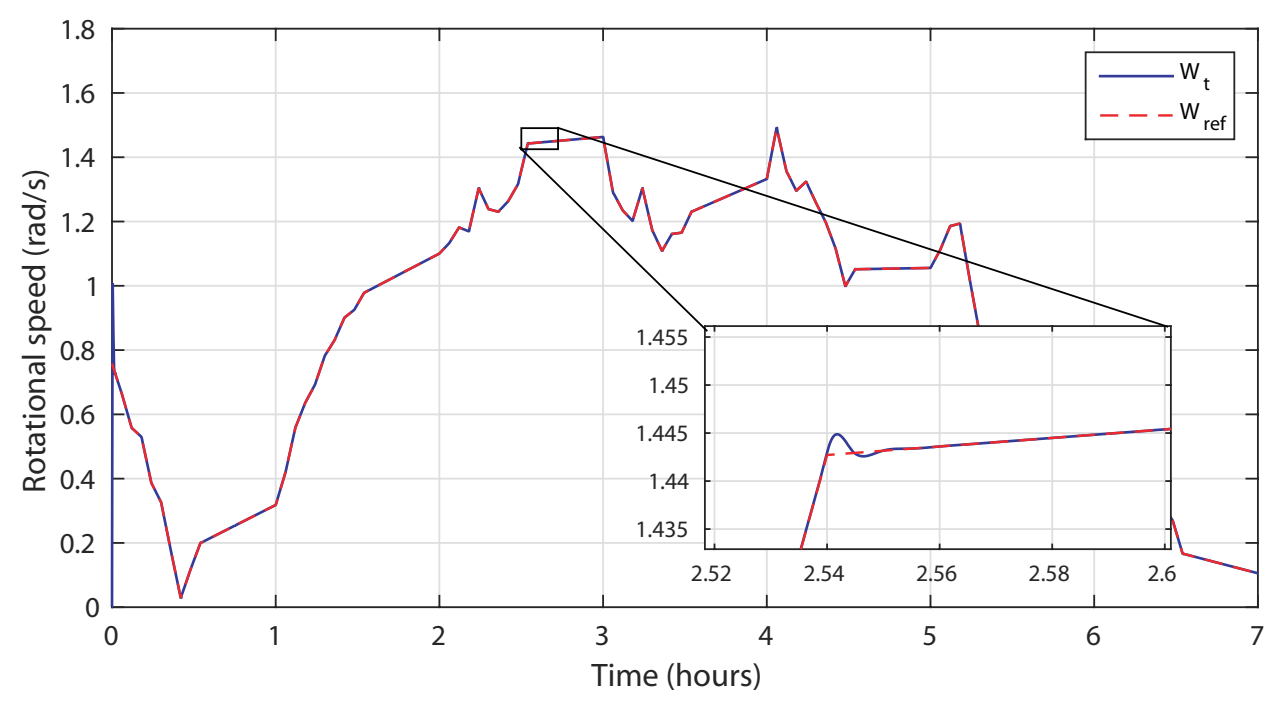

Figure 20. Study case 2: Rotational speed response and its reference.

The response of the hydrodynamic torque is depicted in Figure 21. The torque increases according to the tidal current speed input variation. Figure 22 shows the generated power in the uncontrolled case and the controlled case using the neural fuzzy techniques. The output generated power is improved in terms of average values with $22.4 \%$, which leads to maximizing the energy harnessed by the tidal velocity even in the case of high disturbance.

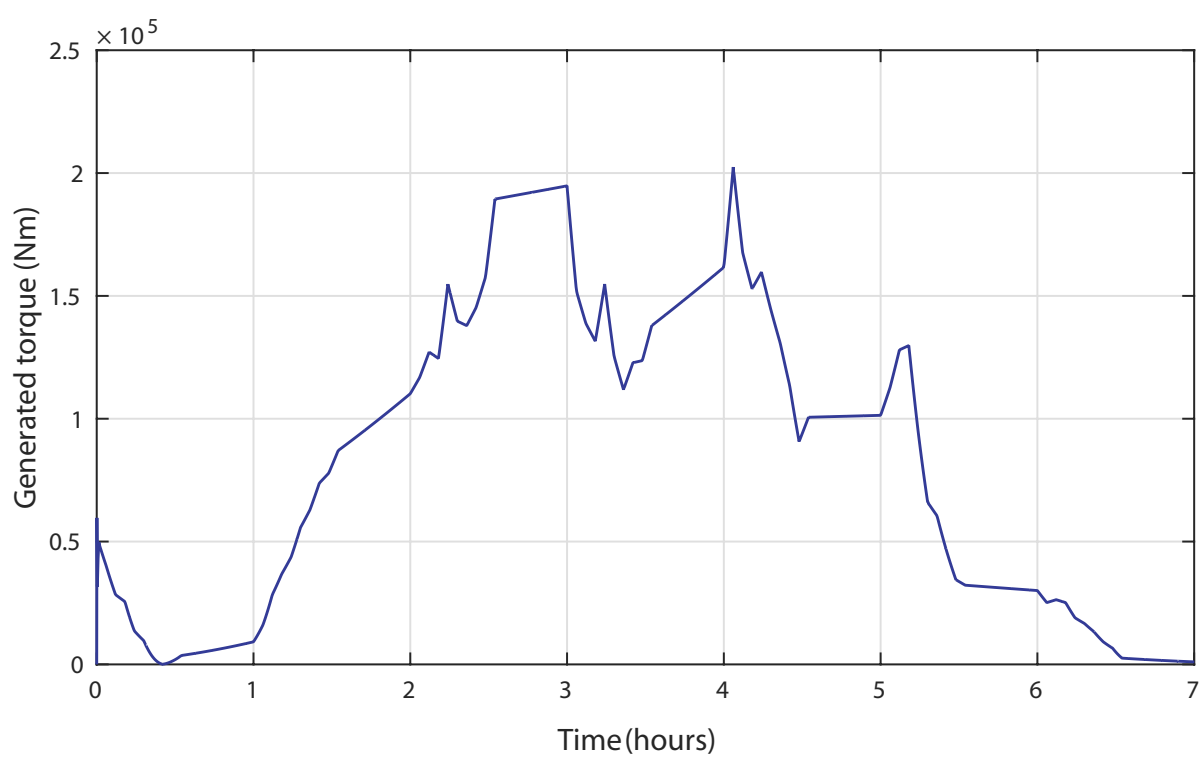

Figure 21. Study case 2: Response of the hydrodynamic torque. 


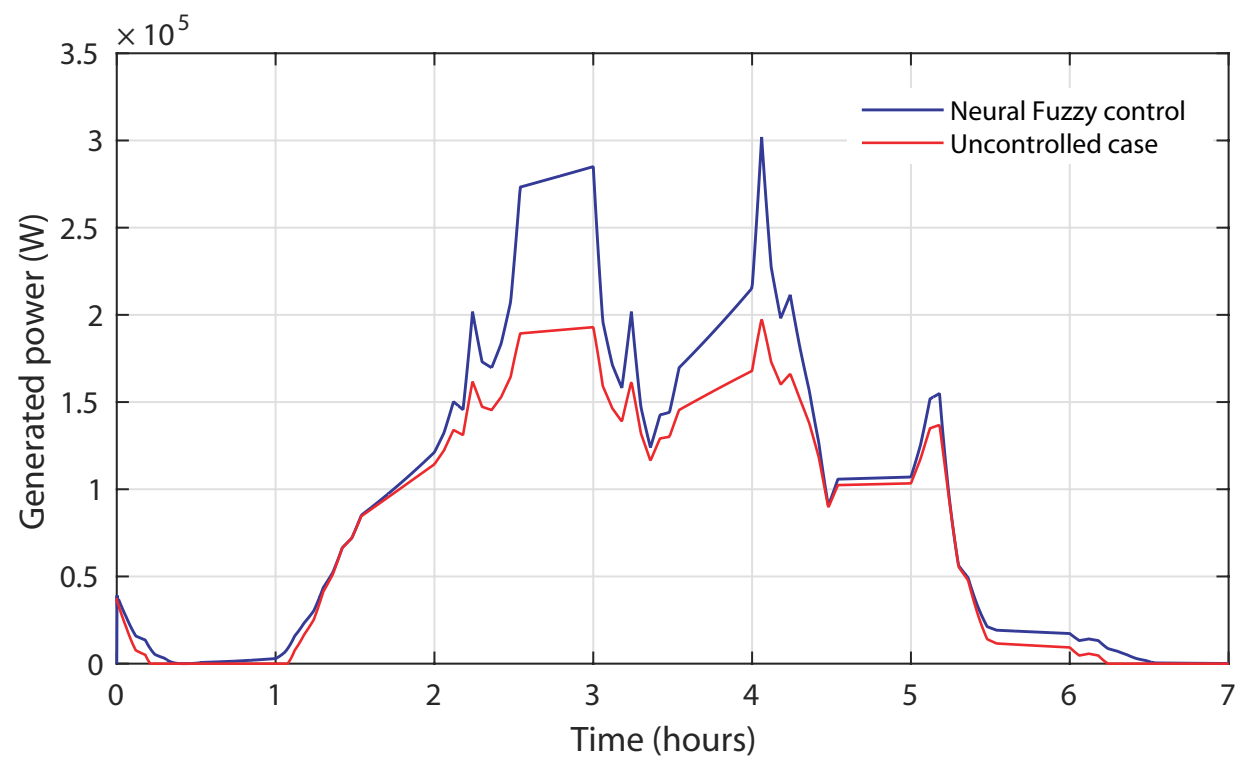

Figure 22. Study case 2: Generated turbine power curve.

\subsection{Disturbance Rejection}

To test the robustness of the proposed control, a disturbance rejection experiment was carried out. The disturbance is injected into the measured signal, which is the rotational speed. The tidal speed input versus time considered starts from $1.5 \mathrm{~m} / \mathrm{s}$ and steps to $3.2 \mathrm{~m} / \mathrm{s}$ at $t=5 \mathrm{~s}$ as shown in Figure 23.

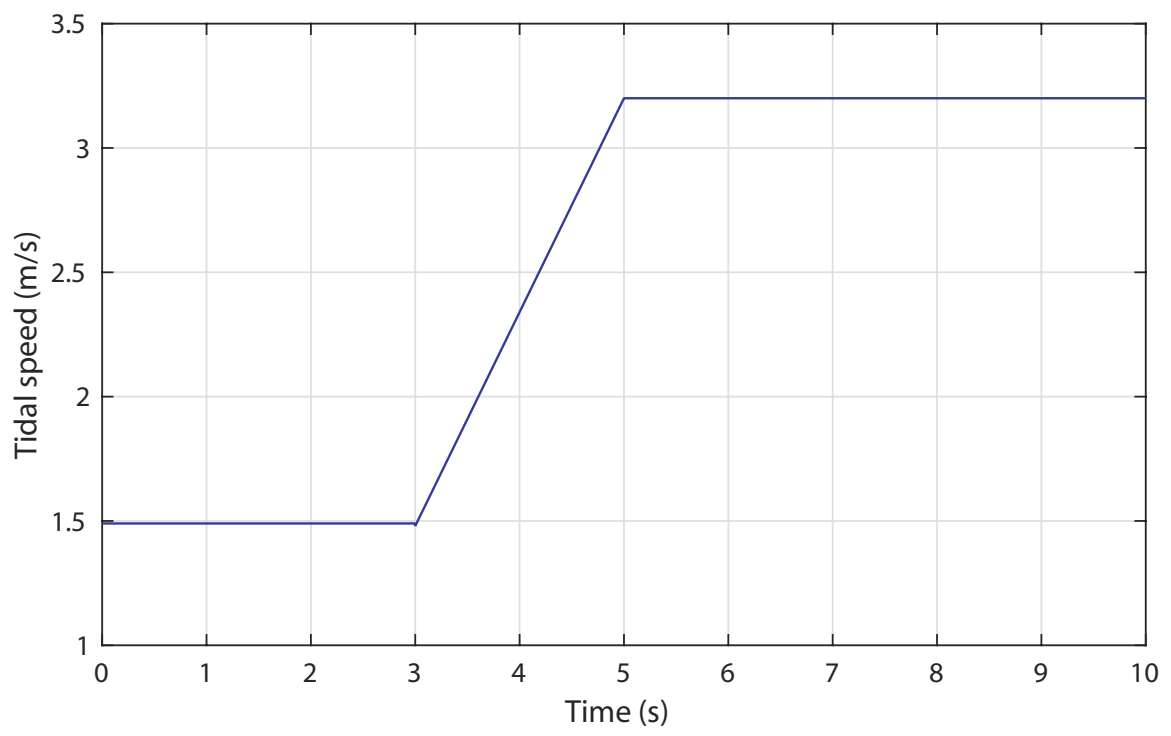

Figure 23. Step tidal speed input.

The measured rotational speed increases according to the tidal current speed from $1.18 \mathrm{rad} / \mathrm{s}$ to $2.53 \mathrm{rad} / \mathrm{s}$ as illustrated in Figure 24. The curve shows an effective tracking performance of the rotational speed. 


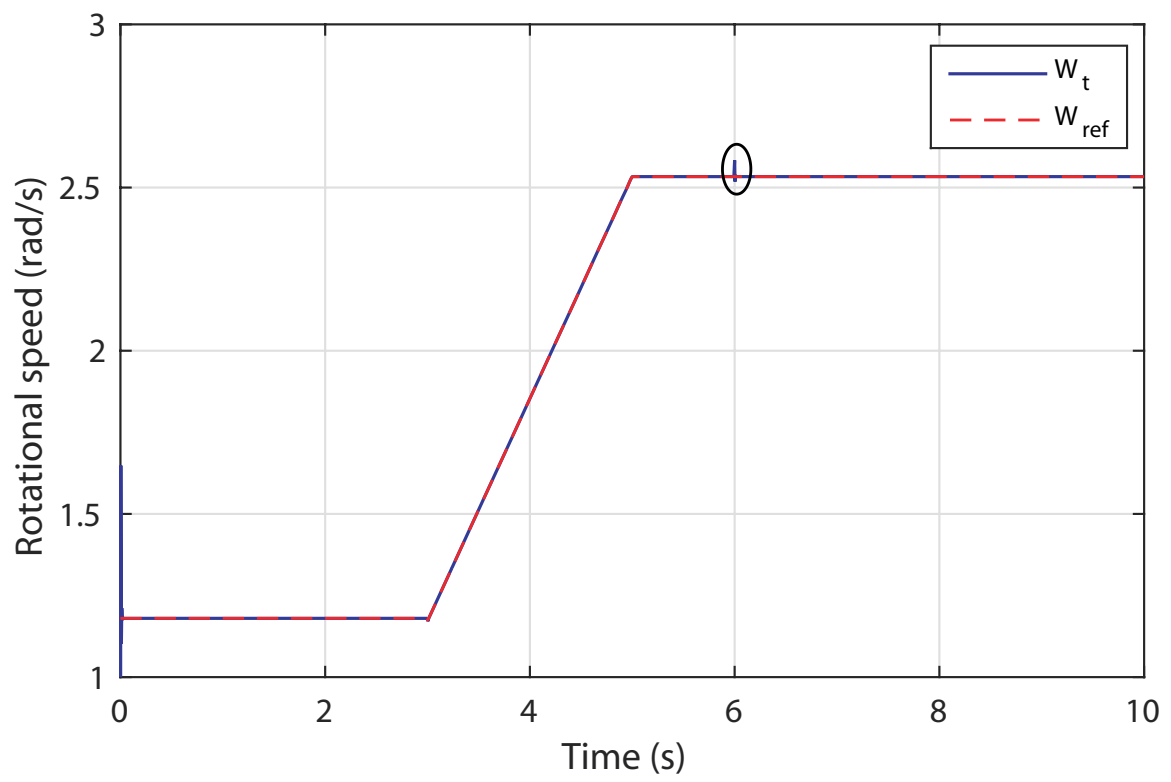

Figure 24. Response of the rotational speed.

The occurrence of the disturbance is injected at $t=6 \mathrm{~s}$ with a $10 \%$ of the average rotational speed as depicted in Figure 25a. In fact, when zooming in on the curve, it can be clearly seen that the controller is able to reject the disturbance in $0.015 \mathrm{~s}$ and allows the system to be stable in the steady-state operation as depicted in Figure 25b. The resulting power coefficient adequately adapts to the disturbance condition and it is noted that the response is closer to the optimum value with 0.4379 .

a)
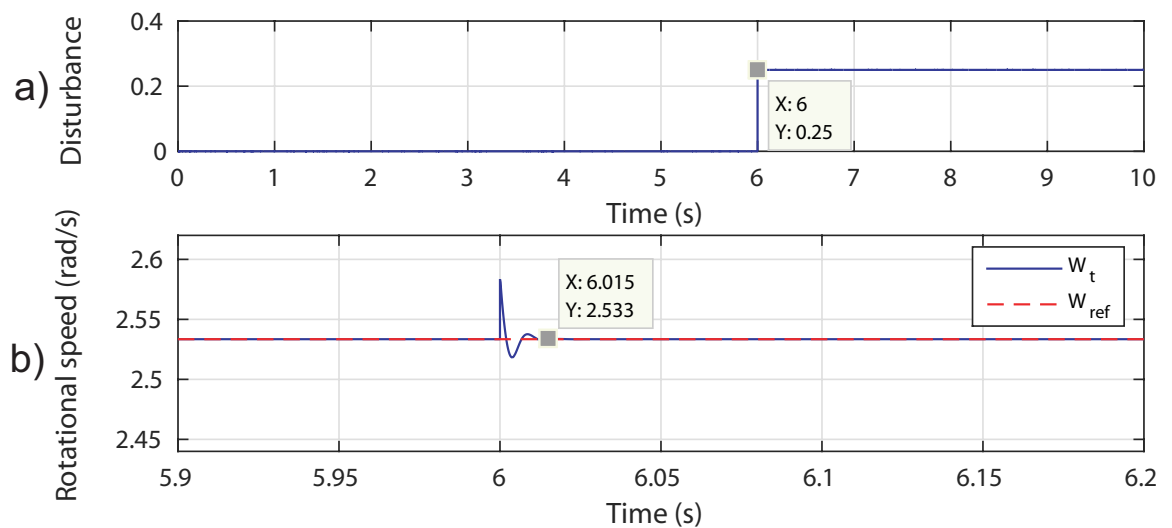

c)

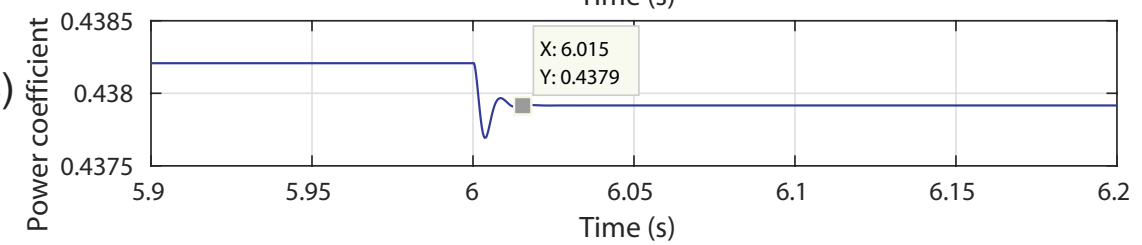

Figure 25. Disturbance rejection at $t=6 \mathrm{~s}$. (a) disturbance occurrence; (b) zoom-in rotational speed versus time; (c) zoom-in power coefficient response.

The generated output power is depicted in Figure 26. The TSG system is is capable of enhancing the output power of $1.48 \mathrm{MW}$ according to a tidal speed of $3.2 \mathrm{~m} / \mathrm{s}$. The implemented control enhances the generated power with a decreased error of approximately $2 \%$ compared to the tolerable supported power by the system. It can be noted that the developed control approaches lead to a power improvement against disturbances. 


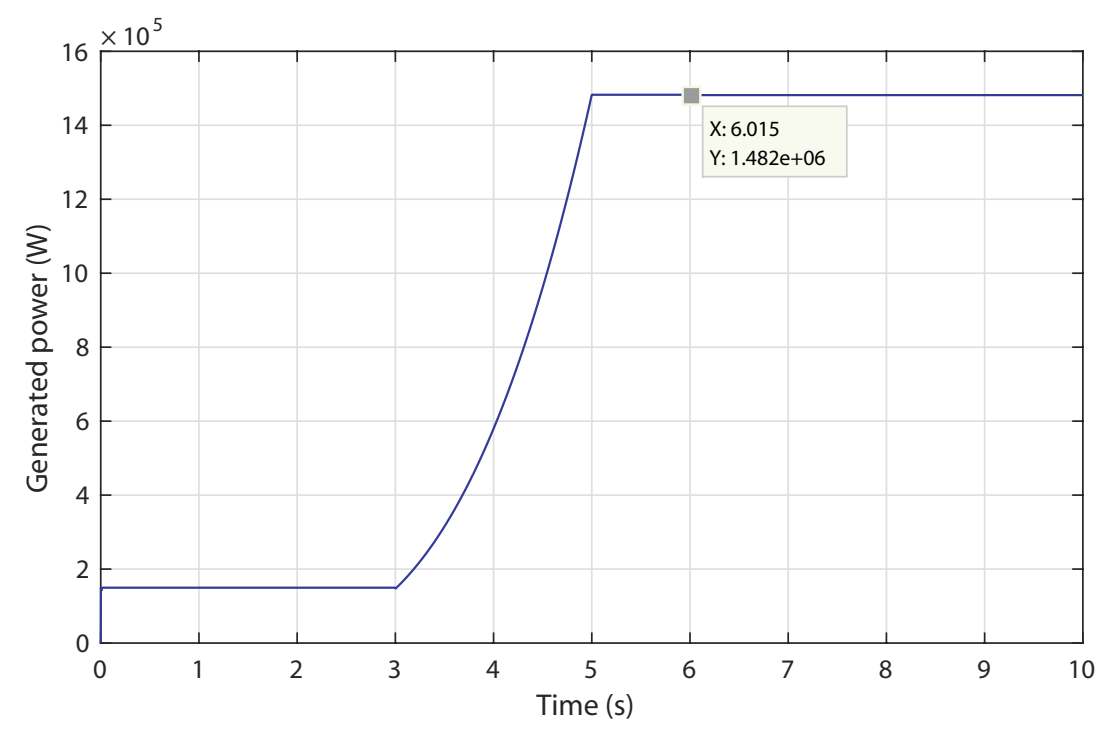

Figure 26. Generated power curve.

\section{Conclusions}

In this article, a tidal stream generator system has been designed and controlled. A hybrid neural fuzzy design has been developed to deal with the power disturbances due to the swell effect.

The hybrid design consists of an ANN-based MPPT approach which adequately generates the reference rotational speed in order to drive coupled with a fuzzy gain schedule that drives the system in the maximum power. The ANN design adaptively changes its weights to provide the suitable trajectory for each marine velocity. The block design is the fuzzy gain scheduling which controls the rotational speed control loop. The fuzzy controller adaptively changes its gains using the designed fuzzy supervisors.

To test the effectiveness of the novel hybrid FGS PI-controller, two realistic tidal sites were investigated. The first scenario is proposed with a variable spring and neap marine velocity provoking swell effect disturbances on the Western coast of Europe. The results found prove that approaches successfully deal with these perturbations that enable the TSG plant to harness the maximum output power. A second scenario based on the realistic data from the Cook Inlet, USA was considered. Comparing with the uncontrolled case, the hybrid neural fuzzy controller shows the power generation improvement offered by the developed control schemes.

Another case of study was considered to assess the robustness of the implemented control strategies under disturbances with an excellent reference tracking. The proposed hybrid FGS-PI control that has been enhanced with an ANN provides very good output power performance improvement from the tidal stream generator system.

This study consists of enhancing the operation of the tidal stream generator system for several study cases by varying the input profile. In effect, the plant is controlled in a way to maximize the harnessed power. The work proves that regulating the tidal turbine in variable speed functioning lead to a high energy yield by operating with a maximum power coefficient.

Author Contributions: Conceptualization, K.G., I.G., S.B., J.H. and A.J.G.; Formal Analysis, K.G.; Investigation, K.G.; Methodology, K.G.; Software, K.G.; Supervision, I.G. , S.B., J.H. and A.J.G.; Validation, I.G. and A.J.G.; Writing, Review and Editing, K.G.

Funding: This research received no external funding.

Acknowledgments: This work was supported by the MINECO through the Research Project DPI2015-70075-R (MINECO/FEDER, UE). The authors would like to thank the collaboration of the Basque Energy Agency (EVE) through Agreement UPV /EHUEVE23/6/2011, the Spanish National Fusion Laboratory (EURATOM-CIEMAT) through Agreement UPV/EHUCIEMAT08/190 and EUSKAMPUS-Campus of International Excellence.

Conflicts of Interest: The authors declare no conflict of interest. 


\section{Abbreviations}

The following abbreviations are used in this manuscript:

$\begin{array}{ll}\text { ANN } & \text { Artificial Neural Network } \\ \text { DFIG } & \text { Doubly Fed Induction Generator } \\ \text { GSC } & \text { Grid Side Converter } \\ \text { IEA } & \text { International Energy Agency } \\ \text { FGS } & \text { Fuzzy Gain Scheduling } \\ \text { IEO } & \text { International Energy Outlook } \\ \text { MPPT } & \text { Maximum Power Point Tracking } \\ \text { MSE } & \text { Mean Square Error } \\ \text { NOAA } & \text { National Oceanic and Atmospheric Administration } \\ \text { ORC } & \text { Optimal Regime Characteristic } \\ \text { PI } & \text { Proportional Integral } \\ \text { PLL } & \text { Phase Locked Loop } \\ \text { PTO } & \text { Power Take Off } \\ \text { PWM } & \text { Pulse Width Modulation } \\ \text { RSC } & \text { Rotor Side Converter } \\ \text { TSG } & \text { Tidal Stream Generator } \\ \text { TST } & \text { Tidal Stream Turbine } \\ \text { NB } & \text { Negative Big } \\ \text { N } & \text { Negative } \\ \text { Z } & \text { Zero } \\ \text { P } & \text { Positive } \\ \text { PB } & \text { Positive Big } \\ & \end{array}$

\section{Notations}

$P_{t, g, n}$

$C_{p}, C_{p \max }$

$\lambda, \lambda_{\text {opt }}$

$\beta, \rho, R$

$V, V_{n}$

$\omega_{t, g}, \omega_{s, r}$

$\omega_{\text {ref }}$

$T_{t s t}, T_{t}, T_{e m}$

$H_{t, g}, T_{s}$

$D_{s h}, K_{s h}, p, \sigma$

$\omega_{\text {slip }}, p$

$U_{s d, s q}, U_{r d, r q}$

$I_{s d, s q}, I_{r d, r q}, i_{m}$

$\varphi_{s d, s q}, \varphi_{r d, r q}$

$L_{s, r}, L_{m}, L_{g}$

$R_{s, r}, R_{g}$

$U_{g d, g q}, U_{g d 1, g q 1}$

$I_{g d, g q}, I_{d c}$

$U_{d c}, c$

$z_{i}, x_{i}, T_{i}$

$\omega_{i, j}, h_{i}$

$u_{k}$

$e(k), \Delta e(k)$

$K_{p}, K_{i}$

$K_{p}^{\prime}, K_{i}^{\prime}$

$\mu_{\mathrm{A} i, B i, C i, D i}$

Turbine, generator and nominal powers (W).

Power coefficient and its maximum.

Optimal speed ratio and its optimal value.

Blade pitch angle (deg), fluid density $\left(\mathrm{kg} / \mathrm{m}^{3}\right)$ and blade radius $(\mathrm{m})$.

Tidal current speed and its nominal value $(\mathrm{m} / \mathrm{s})$.

Rotational speed of turbine and generator, pulsations of the stator and rotor ( $\mathrm{rad} / \mathrm{s})$.

Reference rotational speed ( $\mathrm{rad} / \mathrm{s})$.

Turbine, rotor shaft and electromagnetic torques $(\mathrm{Nm})$.

Turbine and generator inertia constants, sampling time (s).

Stiffness coefficient (Nm/rad), damping coefficient (Nms/rad), leakage factor.

Angular frequency of slip (rad/s), pole pair numbers.

Stator and rotor voltages in $d-q$ frame $(\mathrm{V})$.

Stator and rotor currents in $d-q$ frame, stator magnetizing current (A).

Stator and rotor flux in $d-q$ frame $(\mathrm{Wb})$.

Stator and rotor inductances, magnetizing inductance, grid coupling inductance $(\mathrm{H})$.

Stator and rotor resistances, grid coupling resistance $(\Omega)$.

Grid voltages and terminal voltages of the converter in $d-q$ frame $(\mathrm{V})$.

Grid currents in $d-q$ and DC-link current (A).

DC-link voltage (V), DC-link capacitor (F).

Output neurons, input neurons, threshold terms of the hidden layer.

synaptic weights, number of neurons in the hidden layer.

Fuzzy control law.

The error and the error change.

Fuzzy PI gains.

Normalized fuzzy PI gains.

Grades of the membership functions. 


\section{References}

1. Segura, E.; Morales, R.; Somolinos, J.A.; Lopez, A. Techno-economic challenges of tidal energy conversion systems: Current status and trends. Renew. Sustain. Energy Rev. 2017, 77, 536-550. [CrossRef]

2. World Energy Council. World Energy Resource Marine Energy 2016; Technical Report; World Energy Council: London, UK, 2016; pp. 1-76.

3. Zhang, Y.L.; Lin, Z.; Liu, Q.L. Marine renewable energy in China: Current status and perspectives. Water Sci. Eng. 2014, 7, 288-305.

4. Grabbe, M.; Lalander, E.; Lundin, S.; Leijon, M. A review of the tidal current energy resource in Norway. Renew. Sustain. Energy Rev. 2009, 13, 1898-1909. [CrossRef]

5. Kadiri, M.; Ahmadian, R.; Bockelmann-Evans, B.; Rauen, W.; Falconer, R. A review of the potential water quality impacts of tidal renewable energy systems. Renew. Sustain. Energy Rev. 2012, 16, 329-341. [CrossRef]

6. Stern, N.; Calderon, F. Better Growth, Better Climate: The New Climate Economy Report; The Global Commission on the Economy and Climate: New York, NY, USA, 2014. Available online: http:/ / newclimateeconomy. report/ (accessed on 12 October 2018).

7. EIA, U. International Energy Outlook 2016 with Projections to 2040; Energy Department, Energy Information Administration, Office of Energy Analysis: Washington, DC, USA, 2016.

8. International Energy Agency OECD/IEA. World Energy Outlook 2013, Chapter 6: Renewable Energy Outlook; International Energy Agency OECD/IEA: Paris, France, 2013.

9. IRENA. REmap 2030: A Renewable Energy Roadmap; IRENA: Dhabi, United Arab Emirates, 2014. Available online: www.irena.org/remap (accessed on 12 October 2018).

10. Uihlein, A.; Magagna, D. Wave and tidal current energy-A review of the current state of research beyond technology. Renew. Sustain. Energy Rev. 2016, 58, 1070-1081. [CrossRef]

11. Borthwick, A.G. Marine renewable energy seascape. Engineering 2016, 2, 69-78. [CrossRef]

12. Garrido, A.J.; Garrido, I.; Otaola, E.; Lekube, J.; MZoughi, F.; Ghefiri, K.; Mundackamattam, D.G.; Oleagordia, I. Capture chamber modelling and validation in OWC on-shore devices. In Proceedings of the Region 10 Conference (TENCON), Singapore, 22-25 November 2016; pp. 1682-1685.

13. El Tawil, T.; Charpentier, J.F.; Benbouzid, M. Tidal energy site characterization for marine turbine optimal installation: Case of the Ouessant Island in France. Int. J. Mar. Energy 2017, 18, 57-64. [CrossRef]

14. Bryden, I.G.; Couch, S.J. ME1-marine energy extraction: Tidal resource analysis. Renew. Energy 2006, 31, 133-139. [CrossRef]

15. Myers, L.; Bahaj, A.S. Simulated electrical power potential harnessed by marine current turbine arrays in the Alderney Race. Renew. Energy 2005, 30, 1713-1731. [CrossRef]

16. Winter, A.I. Differences in fundamental design drivers for wind and tidal turbines. In Proceedings of the 2011 IEEE-Spain OCEANS, Santander, Spain, 6-9 June 2011; pp. 1-10.

17. Whitby, B.; Ugalde-Loo, C.E. Performance of pitch and stall regulated tidal stream turbines. IEEE Trans. Sustain. Energy 2014, 5, 64-72. [CrossRef]

18. Hammons, T.J. Tidal power. Proc. IEEE 1993, 81, 419-433. [CrossRef]

19. Choi, J.S.; Jeong, R.G.; Shin, J.H.; Kim, C.K.; Kim, Y.S. New Control Method of Maximum Power Point Tracking for Tidal Energy Generation System. In Proceedings of the International Conference on Electrical Machines and Systems, Seoul, Korea, 8-11 October 2007; pp. 165-168.

20. Rahman, M.L.; Oka, S.; Shirai, Y. Hybrid power generation system using offshore-wind turbine and tidal turbine for power fluctuation compensation (HOT-PC). IEEE Trans. Sustain. Energy 2010, 1, 92-98. [CrossRef]

21. Xiang, D.; Ran, L.; Tavner, P.J.; Yang, S. Control of a doubly fed induction generator in a wind turbine during grid fault ride-through. IEEE Trans. Energy Convers. 2006, 21, 652-662. [CrossRef]

22. Sousounis, M.C.; Shek, J.K.H.; Mueller, M.A. Modelling and control of tidal energy conversion systems with long distance converters. In Proceedings of the 7th IET International Conference on Power Electronics, Machines and Drives (PEMD 2014), Manchester, UK, 8-10 April 2014; pp. 1-6.

23. Munteanu, I.; Bratcu, A.L.; Cutululis, N.A.; Ceanga, E. Optimal Control of Wind Energy Systems: Towards a Global Approach; Springer: Berlin, Germany, 2008.

24. Marzband, M.; Azarinejadian, F.; Savaghebi, M.; Pouresmaeil, E.; Guerrero, J.M.; Lightbody, G. Smart transactive energy framework in grid-connected multiple home microgrids under independent and coalition operations. Renew. Energy 2018, 126, 95-106. [CrossRef] 
25. Tavakoli, M.; Shokridehaki, F.; Marzband, M.; Godina, R.; Pouresmaeil, E. A Two Stage Hierarchical Control Approach for the Optimal Energy Management in Commercial Building Microgrids Based on Local Wind Power and PEVs. Sustain. Cities Soc. 2018, 41, 332-340. [CrossRef]

26. Utkin, V.I. Sliding Modes in Control and Optimization; Springer: Berlin, Germany, 1992.

27. Elghali, S.E.B.; Benbouzid, M.E.H.; Charpentier, J.F.; Ahmed-Ali, T.; Munteanu, I. Experimental Validation of a Marine Current Turbine Simulator: Application to a Permanent Magnet Synchronous Generator-Based System Second-Order Sliding Mode Control. IEEE Trans. Ind. Electron. 2011, 58, 118-126.

28. Feng, Y.; Han, F.; Yu, X. Chattering free full-order sliding-mode control. Automatica 2014, 50, $1310-1314$. [CrossRef]

29. Kalogirou, S.A. Artificial neural networks in renewable energy systems applications: A review. Renew. Sustain. Energy Rev. 2001, 5, 373-401. [CrossRef]

30. Morgan, N.; Bourlard, H.A. Neural networks for statistical recognition of continuous speech. Proc. IEEE 1995, 83, 742-772. [CrossRef]

31. Bilgili, M.; Sahin, B.; Yasar, A. Application of artificial neural networks for the wind speed prediction of target station using reference stations data. Renew. Energy 2007, 32, 2350-2360. [CrossRef]

32. Castro, A.; Carballo, R.; Iglesias, G.; Rabunal, J.R. Performance of artificial neural networks in nearshore wave power prediction. Appl. Soft Comput. 2014, 23, 194-201. [CrossRef]

33. Dounis, A.I.; Kofinas, P.; Alafodimos, C.; Tseles, D. Adaptive fuzzy gain scheduling PID controller for maximum power point tracking of photovoltaic system. Renew. Energy 2013, 60, 202-214. [CrossRef]

34. Chaiyatham, T.; Ngamroo, I. Optimal fuzzy gain scheduling of PID controller of superconducting magnetic energy storage for power system stabilization. Int. J. Innov. Comput. Inf. Control 2013, 9, 651-666.

35. Bahaj, A.S.; Molland, A.F.; Chaplin, J.R.; Batten, W.M.J. Power and thrust measurements of marine current turbines under various hydrodynamic flow conditions in a cavitation tunnel and a towing tank. Renew. Energy 2007, 32, 407-426. [CrossRef]

36. Ghefiri, K.; Bouallègue, S.; Garrido, I.; Garrido, A.J.; Haggège, J. Complementary Power Control for Doubly Fed Induction Generator-Based Tidal Stream Turbine Generation Plants. Energies 2017, 10, 862. [CrossRef]

37. Ghefiri, K.; Bouallègue, S.; Haggège, J. Modeling and SIL simulation of a Tidal Stream device for marine energy conversion. In Proceedings of the 2015 6th International Renewable Energy Congress (IREC), Sousse, Tunisia, 24-26 March 2015; pp. 1-6.

38. Muljadi, E.; Gevorgian, V.; Wright, A.; Donegan, J.; Marnagh, C.; McEntee, J. Turbine Control of a Tidal and River Power Generator: Preprint (No. NREL/CP-5D00-66867); National Renewable Energy Lab.(NREL): Golden, CO, USA, 2016.

39. Fernandez, L.M.; Jurado, F.; Saenz, J.R. Aggregated dynamic model for wind farms with doubly fed induction generator wind turbines. Renew. Energy 2008, 33, 129-140. [CrossRef]

40. Benelghali, S.; Benbouzid, M.E.H.; Charpentier, J.F. Generator systems for marine current turbine applications: A comparative study. IEEE J. Ocean. Eng. 2012, 37, 554-563. [CrossRef]

41. Amundarain, M.; Alberdi, M.; Garrido, A.J.; Garrido, I. Modeling and simulation of wave energy generation plants: Output power control. IEEE Trans. Ind. Electron. 2011, 58, 105-117. [CrossRef]

42. Fan, L.; Kavasseri, R.; Miao, Z.L.; Zhu, C. Modeling of DFIG-based wind farms for SSR analysis. IEEE Trans. Power Deliv. 2010, 25, 2073-2082. [CrossRef]

43. Pena, R.; Clare, J.C.; Asher, G.M. Doubly fed induction generator using back-to-back PWM converters and its application to variable-speed wind-energy generation. IEE Proc.-Electr. Power Appl. 1996, 143, 231-241. [CrossRef]

44. Zhou, D.; Blaabjerg, F.; Lau, M.; Tonnes, M. Optimized reactive power flow of DFIG power converters for better reliability performance considering grid codes. IEEE Trans. Ind. Electron. 2015, 62, 1552-1562. [CrossRef]

45. Muller, S.; Deicke, M.; De Doncker, R.W. Doubly fed induction generator systems for wind turbines. IEEE Ind. Appl. Mag. 2002, 8, 26-33. [CrossRef]

46. Alberdi, M.; Amundarain, M.; Garrido, A.J.; Garrido, I.; Casquero, O.; De la Sen, M. Complementary control of oscillating water column-based wave energy conversion plants to improve the instantaneous power output. IEEE Trans. Energy Convers. 2011, 26, 1021-1032. [CrossRef]

47. Rizzo, S.A.; Scelba, G. ANN based MPPT method for rapidly variable shading conditions. Appl. Energy 2015, 145, 124-132. [CrossRef] 
48. Makarynskyy, O.; Makarynska, D.; Rusu, E.; Gavrilov, A. Filling gaps in wave records with artificial neural networks. Marit. Transp. Exploit. Ocean Coast. Resour. 2005, 2, 1085-1091.

49. Ghefiri, K.; Bouallègue, S.; Garrido, I.; Garrido, A.J.; Haggège, J. Modeling and MPPT control of a Tidal Stream Generator. In Proceedings of the 2017 th International Conference on Control, Decision and Information Technologies (CoDIT'17), Barcelona, Spain, 5-7 April 2017; pp. 1003-1008.

50. Hagan, M.T.; Menhaj, M.B. Training feedforward networks with the Marquardt algorithm. IEEE Trans. Neural Netw. 1994, 5, 989-993. [CrossRef] [PubMed]

51. Wilamowski, B.M.; Yu, H. Improved computation for Levenberg-Marquardt training. IEEE Trans. Neural Netw. 2010, 21, 930-937. [CrossRef] [PubMed]

52. Lewis, M.J.; Neill, S.P.; Hashemi, M.R.; Reza, M. Realistic wave conditions and their influence on quantifying the tidal stream energy resource. Appl. Energy 2014, 136, 495-508. [CrossRef]

53. Zhao, Z.Y.; Tomizuka, M.; Isaka, S. Fuzzy gain scheduling of PID controllers. IEEE Trans. Syst. Man Cybern. 1993, 23, 1392-1398. [CrossRef]

54. Tursini, M.; Parasiliti, F.; Zhang, D. Real-time gain tuning of PI controllers for high-performance PMSM drives. IEEE Trans. Ind. Appl. 2002, 38, 1018-1026. [CrossRef]

55. Bouallègue, S.; Haggège, J.; Ayadi, M.; Benrejeb, M. PID-type fuzzy logic controller tuning based on particle swarm optimization. Eng. Appl. Artif. Intell. 2012, 25, 484-493. [CrossRef]

56. Chen, Y.Y.; Perng, C.F. Input scaling factors in fuzzy control systems. In Proceedings of the 1994 3rd International Fuzzy Systems Conference, Orlando, FL, USA, 26-29 June 1994; pp. 1666-1670.

57. Bedoud, K.; Ali-rachedi, M.; Bahi, T.; Lakel, R. Adaptive fuzzy gain scheduling of PI controller for control of the wind energy conversion systems. Energy Procedia 2015, 74, 211-225. [CrossRef]

58. Qu, L.; Qiao, W. Constant power control of DFIG wind turbines with supercapacitor energy storage. IEEE Trans. Ind. Appl. 2011, 47, 359-367. [CrossRef]

59. Astrom, K.J.; Hagglund, T. Advanced Pid Control; ISA-The Instrumentation, Systems, and Automation Society: Research Triangle Park, NC, USA, 2006.

60. Vilanova, R.; Visioli, A. PID Control in the Third Millennium; Springer: London, UK, 2012.

61. Blaabjerg, F.; Teodorescu, R.; Liserre, M.; Timbus, A.V. Overview of control and grid synchronization for distributed power generation systems. IEEE Trans. Ind. Electron. 2006, 53, 1398-1409. [CrossRef]

62. Zhou, Z.; Benbouzid, M.; Charpentier, J.F.; Scuiller, F.; Tang, T. A review of energy storage technologies for marine current energy systems. Renew. Sustain. Energy Rev. 2013, 18, 390-400. [CrossRef]

63. Alves, J.H.G. Numerical modeling of ocean swell contributions to the global wind-wave climate. Ocean Model. 2006, 11, 98-122. [CrossRef]

64. National Oceanic and Atmospheric Administration (NOAA). Available online: https://tidesandcurrents. noaa.gov/ (accessed on 30 March 2018).

65. Kostaschuk, R.; Best, J.; Villard, P.; Peakall, J.; Franklin, M. Measuring flow velocity and sediment transport with an acoustic Doppler current profiler. Geomorphology 2005, 68, 25-37. [CrossRef]

(C) 2018 by the authors. Licensee MDPI, Basel, Switzerland. This article is an open access article distributed under the terms and conditions of the Creative Commons Attribution (CC BY) license (http://creativecommons.org/licenses/by/4.0/). 